\title{
The Resource Curse, Commodity Prices and Economic Growth*
}

\author{
David I. Harvey (University of Nottingham), Neil M. Kellard \\ (University of Essex), Jakob B. Madsen (Monash University) and \\ Mark E. Wohar (University of Nebraska at Omaha)
}

\author{
December 2017
}

\begin{abstract}
The direction of trend in relative commodity prices has implications for many developing country growth rates. To assess causal underpinnings we create ultralong aggregate series shaped by common factors. Tests show that series present a downward trend over the entire sample which can be broken into 4 regimes of predominantly increasing decline: 1650-1820, 1821-1872, 1873-1946 and 19472010. We argue factors like technology are commensurate with this structure. Finally, we suggest the trend in economic activity is a proxy for such factors and show a negative relationship between trends in commodity prices and World GDP that helps explain the resource curse.
\end{abstract}

Keywords: Primary commodities; Prebisch-Singer hypothesis; Economic growth; Structural breaks; Cycles; Resource Curse.

JEL Classification: O13; C22.

*This chapter is an earlier version of a paper that is now published in World Development (see Harvey, David I., Kellard, Neil M., Madsen, Jakob B and Wohar, Mark E. (2017) 'Long-Run Commodity Prices, Economic Growth and Interest Rates: 17th Century to the Present Day.' World Development, 89. pp. 57-70). Neil Kellard gratefully acknowledges support from grant number ES/L011859/1, from the Business and Local Government Data Research Centre, and funded by the Economic and Social Research Council. Our thanks to Cong Wang for excellent research assistantship, and Tomoyoshi Yabu for providing GAUSS code. The opinions expressed in the paper and any remaining errors remain our responsibility. Address correspondence to: Neil Kellard, Essex Finance Centre, Essex Business School, University of Essex, Wivenhoe Park, Colchester, CO4 3SQ, UK. Tel: +44 (0)1206 874153. E-mail: nkellard@essex.ac.uk. 


\title{
The Resource Curse, Commodity Prices and Economic Growth
}

\author{
December 2017
}

\begin{abstract}
The direction of trend in relative commodity prices has implications for many developing country growth rates. To assess causal underpinnings we create ultralong aggregate series shaped by common factors. Tests show that series present a downward trend over the entire sample which can be broken into 4 regimes of predominantly increasing decline: 1650-1820, 1821-1872, 1873-1946 and 19472010. We argue factors like technology are commensurate with this structure. Finally, we suggest the trend in economic activity proxies for such factors and show a negative relationship between trends in commodity prices and World GDP that explains the resource curse.
\end{abstract}

Keywords: Primary commodities; Prebisch-Singer hypothesis; Economic growth; Structural breaks; Cycles; Resource Curse.

JEL Classification: O13; C22.

\section{Introduction}

The recent 'food crisis' in 2008 starkly demonstrated the importance of global commodities markets. In particular, sharply rising prices for commodities such as wheat, maize, rice and oil pushed many vulnerable groups deeper into poverty (see Ivanic and 
Martin, 2008). ${ }^{1}$ In any case, the behaviour of primary commodity prices is typically important to many developing countries, wherein a significant proportion of national income is often generated by a small number of primary products (see Harvey et al., 2010). ${ }^{2}$ The nature and causes of movements in primary commodity prices therefore have significant implications for growth and poverty reduction policies in developing countries.

Analysis of long-run commodity prices is dominated by the Prebisch-Singer (PS) hypothesis which implies a secular, negative trend in commodity prices relative to manufactures. ${ }^{3}$ Possible theoretical rationales include low income elasticities of demand for commodities, asymmetric market structures that result from comparatively homogeneous commodity producers generating highly competitive commodity markets whilst facing oligopolistic manufacturing markets, and technological and productivity differentials between core (industrial) and periphery (non-industrial) countries. If a country's export commodities present long-run downward trends in their relative prices, the policy advice is typically to diversify the export mix to include significant proportions of manufactures and/or services. Additionally, as is noted in Arezki et al. (2014a), understanding the trend and other time series characteristics should enable improved forecasting of commodity price movements.

Empirical evidence examining the PS hypothesis provides an ambiguous picture. The vast majority of recent studies employ the Grilli and Yang (1988) dataset of 24 annual non-fuel primary commodity prices which commences in $1900 .{ }^{4}$ However, the

\footnotetext{
${ }^{1}$ In 1990-1992, it was estimated that 817 million people, approximately $20 \%$ of the global population, were undernourished. In 2005-2007, this was estimated to be 830 million people, around $16 \%$. However, with current estimates at more than one billion undernourished people, this represents a return to approximately $20 \%$ of the world population (see Millennium Development Goals Report, 2010).

${ }^{2}$ For example, the World Bank's World Development Indicators suggests that primary commodities contributed $50 \%$ of the total merchandise exports of developing countries in 2007. Strikingly, reliance on primary commodities is even higher in Sub-Saharan Africa and the Higher Indebted Poorer Countries, accounting for approximately $66 \%$ and $80 \%$ of merchandise exports respectively.

${ }^{3}$ See Prebisch (1950) and Singer (1950).

${ }^{4}$ Earlier work, not employing the GY dataset, includes Spraos (1980), Sapsford (1985) and Thirwall and Bergevin (1985).
} 
relatively large variance of commodity prices (see Deaton, 1999) and the possibility of trend structural breaks inhibits statistical determination of any trend magnitude and direction with this sample size. A possible approach to address this issue is to provide greater degrees of freedom via a backwards extension of the sample. Recently, Harvey et al. (2010) and Arezki et al. (2014b) employ a unique disaggregated dataset, comprised of 25 separate commodity time series and spanning the 17 th to the 21 st centuries.

Although there is a large body of literature examining the veracity of the PS hypothesis, there are far fewer attempts to establish a plausible rationale for any estimated trend and associated breaks. In many ways, this is understandable; reliable historical data on possible causal variables such as technology differentials, relative market structures or income elasticities of demand are clearly difficult to source. However, the primary goal of this chapter is to explore the causal underpinnings of long-run commodity prices and hence to provide input to long-range forecasting and policy design. To circumvent the lack of data we suggest a threefold approach. Firstly, aggregate measures of relative commodity prices would be useful over a very long time frame. An aggregate measure of commodity price movements should smooth the idiosyncratic effects of individual commodity prices and provide a summary series shaped primarily by common factors. Secondly, the time series characteristics of these new series can subsequently be cross-referenced with the existing economic history literature to elucidate possible common factors. Finally, we suggest that the trend growth rate of economic activity, data that is available over an historical timeframe, is a useful proxy for these common factors (see, for example, Sachs and McArthur, 2002).

In this chapter, our first contribution is to collect a large historical dataset on the export values of 23 individual commodities; not a straightforward task. This new data is then used as weights when combined with updated individual commodity series from Harvey et al. (2010) to create aggregate annual series beginning in 1650 and 
running continuously until 2010. Subsequently, our second contribution is to use the new aggregate series to examine the statistical properties of relative commodity prices over the very long-run. Given the well known problems of identifying the order of integration of price series, and the pervasive influence of any unit root/stationarity pre-tests on subsequent tests of commodity time series characteristics (see Harvey et al., 2010), we apply trend tests and multiple trend break tests which are robust to whether or not the series under consideration contains a unit root. The results show that the trend path of our new aggregate series can be split into four regimes (i.e., 1650 to the early 1820 s, the early 1820 s to the early 1870 s, the early 1870 s to the mid-1940s, and the mid-1940s to 2010). Through all but the second regime, a long-run downward trend can be clearly detected, giving new historical support to the PS hypothesis.

Our understanding of the regimes suggested above can be deepened by the extant economic history literature. For example, the 19th century terms of trade boom in the poor periphery suggested by Williamson (2008) is formally dated by our analysis as existing during our second regime from the 1820s to the 1870s. It is suggested this singular boom was driven by factors such as growing demand from the industrialising core of European countries, falling transport costs, technological innovations in manufacturing and the associated liberalisation of trade. In a sense, this is analogous to the early 21st century, as China, India and other emerging nations rapidly industrialise, shifting upward the demand curve for a range of primary commodities. This reminds policymakers and forecasters that prices can remain above trend for many years before returning to a long-run negative growth path and that care should be taken not to treat increases in export income as permanant.

Our third contribution is to examine whether trend breaks in commodity-relevant economic activity coincide with those previously identified for relative commodity prices. It is shown that UK GDP presents an upward trend break in the 1820 s and World GDP in the 1870s and 1950s. These dates are closely associated with those 
found for commodity prices. Additionally, it should be noted that although relative commodity prices present a secular decline over the 17th and 18th centuries, this was at a slower rate as compared with the 20th century. This is matched by the increasing rate of trend growth in economic activity as the sample increases suggesting that the economic forces behind the PS hypothesis intensified during the 1900s and are captured by the trend rate of GDP.

How does this add to our current understanding of commodity price movements? The theory of such movements are currently not well developed or evidenced (see Deaton and Laroque, 2003). Important recent work such as Erten and Ocampo (2013) primarily concentrates on medium-run or cyclical movements around the long-run trend. Building on the idea that changes in demand influence cyclical movements around the trend, they provide some empirical evidence that commodity price supercycles follow World GDP over the period 1865 to 2010. On the other hand, Deaton and Laroque (2003) derive a more formal model with a supply function that adjusts positively to the gap between the current market price and some constant long-run mean. Theoretically, it can then be shown that supply, not economic activity, is cointegrated with commodity prices. In both cases, the underlying long-run trend in commodity prices itself is removed or assumed equal to zero. In this chapter, we provide new evidence that this long-run trend can be negative and time-varying, and moreover, that it is negatively correlated with the positive and time-varying trend in economic growth. This latter relationship describes an important channel by which the resource curse has operated. For example, as industrial core growth rates rose during the 20th century, the real commodity prices important to a primarily commodity-exporting periphery fell dramatically, exacerbating the Great Divergence in economic growth rates between the core and poorer periphery. Finally, we note that although long-run forecasts of commodity prices can employ univariate time series models, they may therefore be usefully improved by including forecasts of future economic growth. 
The remainder of the chapter is organised as follows. Section 2 outlines the extant literature and the theory, section 3 the new data, whilst section 4 describes the empirical methodology. The empirical results and associated discussion are presented in section 5 , and section 6 concludes.

\section{Literature and Theory}

\section{$2.1 \quad$ Long-run trends}

As noted in the previous section, empirical research assessing the PS hypothesis provides mixed results. For example, assuming that logarithms of prices are represented appropriately by a pure trend stationary process, Grilli and Yang (1988) find support for the PS hypothesis, reporting a weighted aggregate real index decline of $0.6 \%$ per annum from 1900-1986. ${ }^{5}$ On the other hand, Zanias (2005) employs the same GrilliYang index extended to 1998, identifies two structural breaks (1920 and 1984) and shows the 20th century decline in commodity prices is almost exclusively explained by these shifts in the mean as opposed to any gradual trending effect. Moreover, empirical results within the literature are often conditional on the assumed order of integration of the relative price processes (see Kim et al., 2003) and whether structural breaks are allowed in the underlying mean or trend function (see Harvey et al., 2010, and Yamada and Yoon, 2014).

To provide more observations with which to estimate a possible trend, some papers have taken a longer historical perspective. Addressing this issue, Cashin and McDer-

\footnotetext{
${ }^{5}$ The extant literature either employs aggregate or disaggregated data. For example, inter alios, Sapsford (1985), Grilli and Yang (1988), Cuddington and Urzúa (1989), Powell (1991), Ardeni and Wright (1992), Sapsford et al. (1992), Reinhart and Wickham (1994) and Zanias (2005) examine trends in aggregate commodity price indexes. However, Cuddington (1992), Leon and Soto (1997), Badillo et al. (1999), Newbold et al. (2000), Kim et al. (2003), Kellard and Wohar (2006), Balagtas and Holt (2009), Harvey et al. (2010) and Ghoshray (2011) examine trends in individual commodity prices. Good summaries of this literature can be found in Greenaway and Morgan (1999) and Cuddington et al. (2007).
} 
mott (2002) employ "the longest publicly available dataset", the industrial commodity price index of The Economist, covering the period 1862-1999. Their results suggest a downward trend of $1.3 \%$ per annum in real commodity prices with no breaks in the trend function. More recently, using their disaggregated dataset of 25 separate commodities from 1650-2005, Harvey et al. (2010) circumvent any order of integration issues by applying test procedures for the presence of a single linear trend and a broken trend which are robust to whether shocks are generated by an $\mathrm{I}(0)$ or $\mathrm{I}(1)$ process. Interestingly, results show that five price series (Aluminum, Banana, Rice, Sugar and Tea) present a significant and downward trend over all or some fraction of the sample period. Of the remainder, nineteen reveal a zero trend (Beef, Coal, Cocoa, Coffee, Copper, Cotton, Gold, Hide, Jute, Lamb, Lead, Nickel, Oil, Pig Iron, Silver, Tin, Wheat, Wool and Zinc), whilst only Tobacco has a significant positive trend over the full sample period. ${ }^{6}$ Finally, Arezki et al. (2014b) also employs the Harvey et al. (2010) dataset but applies panel stationarity tests to assess integration order whilst allowing for multiple structural breaks. The panel tests classify the series as stationary and subsequently a linear trend model is fitted to individual price series before and after identified breaks. This piecewise regression suggests that the majority of segmented trends are negative.

\subsection{Theory}

The theory of either long-run trend or cyclical movements about the trend are not well developed or evidenced (see Deaton and Laroque, 2003). As noted in the introduction, rationales for the trend include low income elasticities of demand for commodities, technological and productivity differentials or asymmetric market structures between the oligopolistic, manufacturing core and the competitive, commodity-producing south.

\footnotetext{
${ }^{6}$ The original Harvey et al. (2010) article indicated that eleven commodities presented a downward trend, but the authors subsequently identified data construction errors arising from the incorrect conversion of some US dollar prices to British pound sterling; the corrected results are given in Harvey et al. (2012) and the corrected data set is available from the authors on request.
} 
Although there is a voluminous literature estimating the long-run trend properties of relative commodity prices, given the difficulties in measuring possible causal factors such as technological differentials, particularly over long-historical time spans, it is therefore not surprising that there is very little work exploring any multivariate association. However, a recent, partial equilibrium model is provided by Deaton and Laroque (2003). Assume that:

$$
y_{t}=y_{t-1}+\varepsilon_{t}^{y}
$$

where $y_{t}$ represents the logarithm of world income. Using a standard log-linear demand function, it can therefore be written:

$$
d_{t}=\alpha y_{t}-\beta p_{t}+\gamma+\varepsilon_{t}^{d}
$$

where $d_{t}$ is demand and $p_{t}$ is the world price for an internationally traded commodity. Moreover, a supply function can be stated:

$$
s_{t}=s_{t-1}+\delta\left(p_{t}-p^{*}\right)+\varepsilon_{t}^{s}
$$

where $s_{t}$ is current supply as a function of last period's supply and the difference between current price and some constant price $p^{*}$, which is the marginal cost of production or extraction of the primary commodity. Assuming $\delta>0$, the supply function embodies the ideas of Lewis (1954), that although the current price may remain above $p^{*}$ for some time, eventually enough supply is forthcoming to adjust price downwards. In particular, Lewis thought that the existence in some geographical areas of (almost) infinite supplies of labour at the subsistence wage, meant that enough supply would be generated to move prices to $p^{*}$ in the long-run. Deaton and Laroque (2003) show that these three equations have some interesting implications. For example, after equalising 
supply and demand, it can be shown that:

$$
\Delta s_{t}=(\beta+\delta)^{-1}\left[\delta\left(\alpha y_{t-1}-s_{t-1}\right)+\alpha \delta \Delta y_{t}+\delta \gamma-\delta \beta p^{*}+\delta \varepsilon_{t}^{d}+\beta \varepsilon_{t}^{s}\right]
$$

and

$$
p_{t}-p^{*}=(\beta+\delta)^{-1}\left[\beta\left(p_{t-1}-p^{*}\right)+\alpha \Delta y_{t}+\Delta \varepsilon_{t}^{d}-\varepsilon_{t}^{s}\right]
$$

where (4) suggests that it is income and supply which are cointegrated ${ }^{7}$ and strikingly, (5) implies that price is a zero-trend stationary process. Of course, we note that the long-run price could instead be a slowly evolving or trending variable $p_{t}^{*}$ which is a function of aforementioned variables like technology or market structure. Replacing $p^{*}$ with $p_{t}^{*}$ in $(5)$ would also allow price to be a more general process and nest more of the empirical evidence presented by the literature.

Providing a testable functional form for $p_{t}^{*}$ is difficult given the data limitations explained earlier. However, a useful proxy for the factors affecting $p_{t}^{*}$ might be the trend growth rate of economic activity, $y_{t}^{*}$. For example, inter alios, Sachs and McArthur (2002) stress that technological innovation is a fundamental driver of long-run economic growth. Moreover, increased market concentration can be seen as both a precursor to, and a result of, technological change (see Lima, 2000). Certainly one could also argue that relatively strong economic growth in the core over the majority of the 19 th and 20th century has encouraged successful manufacturing firms to tend towards oligopoly at an international level. Conversely, sources of primary commodity supply multiply, partially in response to the structural adjustment policies adopted by indebted developing countries. Thus, this type of economic growth is likely to exert downward pressure on relative commodity prices over the very long-run. A simple bivariate function might be:

$$
p_{t}=\kappa+\lambda y_{t}+\varepsilon_{t}^{p}
$$

\footnotetext{
${ }^{7}$ Deaton and Laroque (2003) find limited evidence for this claim but suggest that cointegration tests lack power over their 20th century data set.
} 
where we expect $\lambda<0$. Of course, any structural breaks in the trend of commodity prices would also be correlated with breaks in trend income. We shall assess the evidence for these conjectures in the later results section. However, we would first posit that instead of examining indivdual commodity price series, an aggregate measure would be more useful over the very long-run. Such measures will smooth idiosyncratic effects and provide series more shaped by common factors that are therefore (i) easier to identify from the economic history literature and (ii) potentially proxied by the trend growth rate of income. The construction of such an aggregate index is discussed in the next section.

\section{Historical Exports and Aggregate Data}

The often employed Grilli-Yang dataset comprises twenty-four, internationally traded, non-fuel commodities. ${ }^{8}$ Each annual nominal commodity price series (in US dollars) is deflated by the United Nations Manufacturers Unit Value (MUV) index, the MUV series reflecting the unit values of manufacturing exports from a number of industrial countries. Although a number of papers in the extant literature examine the twentyfour commodities separately, many employ Grilli and Yang's weighted aggregate real index to summarise the behaviour of relative commodity prices as a whole. ${ }^{9}$

As noted in the introduction, the Grilli-Yang dataset begins in 1900, primarily because this is the starting date for the MUV series; however, commodity and manufacturing price data can be sampled backwards well before this time. Given the extensive interest in modeling and analyzing the long-run trends of relative commodity prices, it would appear important to utilize as much of the existing data as is sensibly possible. To do this, Harvey et al. (2010) created a large and representative dataset of twenty-five

\footnotetext{
${ }^{8}$ The commodities are Aluminum, Banana, Beef, Cocoa, Coffee, Copper, Cotton, Hide, Jute, Lamb, Lead, Maize, Palm Oil, Rice, Rubber, Silver, Sugar, Tea, Timber, Tin, Tobacco, Wheat, Wool and Zinc.

${ }^{9}$ The 1977-1979 values of world exports of each commodity are used as weights.
} 
relative commodity price series ${ }^{10}$ (nominal prices in British pound sterling ${ }^{11}$ ) covering a 356 year period from 1650 to $2005 .{ }^{12}$ However, as a result of employing all available data, the series are of unequal lengths. Specifically, twelve series begin in the 17th century (Beef, Coal, Cotton, Gold, Lamb, Lead, Rice, Silver, Sugar, Tea, Wheat and Wool), three series begin in the 18th century (Coffee, Tobacco and Pig Iron), eight series begin in the 19th century (Aluminum, Cocoa, Copper, Hide, Nickel, Oil, Tin and Zinc) and two start from 1900 (Banana and Jute). Twenty of these commodities are also found in the Grilli-Yang dataset and twenty-three are non-fuel. Each nominal commodity price was deflated by a historical price index of manufactures (HPIM), stretching back to $1650 .{ }^{13}$

Harvey et al. (2010) assess the properties of the twenty-five ultra-long commodity prices separately. However, given the tendency in the literature to also examine aggregate commodity series, it would appear useful to construct an ultra-long aggregate series. Of course, this is not a trivial task, in particular because prices and weights series for all commodities are not available uniformly over the period 1650 to the present day. Let the Commodity Composite Price Index (CCPI) be the weighted average of twenty-three Harvey et al. (2010) commodities, where the weights reflect the importance of each commodity in total commodity trade. ${ }^{14}$ When constructing the CCPI, the following steps have been followed. First, the commodity price index (CPI) is calculated using $\sum_{i=1}^{N} w_{i t} p_{i t}$, where $w_{i t}$ and $p_{i t}$ respectively represent the weight and price of the $i$ th commodity in a particular year $t$. If prices and weights are available

\footnotetext{
${ }^{10}$ See the appendix of Harvey et al. (2010) for a fuller description of the source of each price.

${ }^{11}$ British pound sterling is used because the US did not have its own currency before independence in 1776 .

${ }^{12}$ Although it is possible to get data for commodity prices from before 1650 , we could find no reliable source of manufacturing prices.

${ }^{13}$ For details on the construction of HPIM see Harvey et al. (2010).

${ }^{14}$ In this paper, we employ the extended Harvey et al. (2010) commodity and manufacturing price dataset that runs from 1650 to 2010. Additionally, we removed gold and silver from the original list of twenty-five commodities. There is no clear distinction between monetary gold/silver and commodity gold/silver imports in the US Geological Survey data; this could create a distortion, as, for example, monetary gold and silver were heavily imported during the two world-war eras.
} 
for $N-1$ commodities in the first $t=1, \ldots, x$ years and then for $N$ commodities in the next $t=x+1, \ldots, y$ years, individual CPI series are first constructed for each period $t=1, \ldots, x+1$ and $t=x+1, \ldots, y$ using data on $N-1$ and $N$ commodities, respectively. Next, denote by $w_{i, x+1}^{N-1}$ and $w_{i, x+1}^{N}$ the weights employed in these two schemes for the overlapping year $t=x+1$. Then, using the ratio $\sum_{i=1}^{N} w_{i, x+1}^{N} p_{i, x+1} / \sum_{i=1}^{N-1} w_{i, x+1}^{N-1} p_{i, x+1}$, the aggregate series is created by multiplying the ratio by the individual CPI values for the $t=1, \ldots, x$ period and splicing the individual series together to assemble the CCPI.

Several benchmark years, namely 1830, 1860, 1900, 1912, 1928, 1937, 1950, 1975 and 2006 are used to calculate the weights of commodities. Specifically, exports of commodities from the commodity-dependent price-taking economies (the periphery ${ }^{15}$ ) are used as weights. ${ }^{16}$ To be clear, the export value of the $i$ th commodity is divided by the total export value of all selected $N$ commodities in year $t$ to get the weight, $w_{i t}$, of the $i$ th commodity in year $t$. The periphery consists of Asia (excluding Russia), Africa and South America. The benchmark dates are predominantly dictated by data availability; in particular, data on commodity exports are not available before 1830 on a world scale and it is doubtful that the scant import data that are available for a couple of industrialized countries before 1830 are representative of commodity exports for the periphery. In terms of composition of traded commodities there has been a marked change over time. Sugar, textile fibres, coffee, tea and cocoa were the main export items in 1830 and came predominantly from Asia and South America. Of course, energy and metals have recently become the dominant commodities in world trade.

The benchmark years are subsequently linearly interpolated to get weighted series for each commodity on an annual basis. Specifically, interpolation is applied between

\footnotetext{
${ }^{15}$ Blattman et al. (2007) adopts the distinction between the periphery and the core (industrial leaders).

${ }^{16}$ The primary source for the weights to 1937 is 'Commodity Structure of Third World Exports 18301937' by Paul Bairoch and Bouda Etemad. The sources for subsequent weights are UN International Trade Statistics Yearbooks and the UNCTADstat Commodity Trade Matrix. For more details and a full list of sources, see the Data Appendix.
} 
the benchmark years from 1830 to 2006; to complete the series, 1830 weights are used before 1830 and 2006 weights are used after 2006. Although weights before 1830 are kept constant due to unavailability of data, the weights of commodities have been calculated such that their sum remains 100 in each year. For years where price data is unavailable for a few commodities, weights for those commodities in those years are set to zero under the assumption that a commodity has no value or weight when the price is zero. This leads to the construction of the CCPI covering a 361 year period from 1650 to 2010 .

Finally, note that another comparator index was also created, a non-oil version of the Commodity Composite Price Index (CCPI'). Figure 1 shows the logarithms of CCPI and $\mathrm{CCPI}^{\prime}$, revealing a close similarity and apparent downward trend in both series over the full sample period. CCPI and CCPI' will be empirically examined over the full sample; the unbroken trend analysis is applied to a sub-sample of these series (1900-2008), allowing for a more direct comparison with an updated version of the Grilli-Yang non-fuel weighted aggregate real index (GYCPI). ${ }^{17}$ Figure 2 plots the logarithms of these indices over 1900 to 2008. Notably (and as might be expected), the logarithms of CCPI, CCPI' and GYCPI appear to move in a relatively consistent manner over the course of the 20th century. Of course, differences will arise, even between these similar series. For example, while CCPI and $\mathrm{CCPI}^{\prime}$ are constructed using variable weights and the HPIM deflator, GYCPI uses constant weights from 1977-79 and the MUV deflator. In particular, Figure 3 illustrates how HPIM compares with the MUV index for the period since 1900, over which the MUV index is available. In absolute terms the difference is not large and thus is reflected in a very high correlation coefficient of 0.993. However, and as can be observed in Figure 3, in relative terms there are a few significant differences, most notably during the period 1914-1945, where the MUV index is often $25 \%$ below our index. As noted by Harvey et al. (2010), this result

\footnotetext{
${ }^{17}$ The authors thank Stephan Pfaffenzeller for providing the extended GYCPI series from 1900 to 2008.
} 
suggests that export unit values used to construct the MUV index are potentially biased measures of price movements, particularly when long data series are considered. ${ }^{18}$

\section{Empirical methodology}

\subsection{Testing for a linear trend}

We initially consider the following data generating process (DGP) for $p_{t}$, the logarithm of relative commodity prices:

$$
\begin{aligned}
& p_{t}=\alpha+\beta t+u_{t}, \quad t=1, \ldots, T \\
& u_{t}=\rho u_{t-1}+\varepsilon_{t}, \quad t=2, \ldots, T
\end{aligned}
$$

with $u_{1}=\varepsilon_{1}$, where $\varepsilon_{t}$ is assumed to follow a stationary process. To permit the errors $u_{t}$ to be either $\mathrm{I}(0)$ or $\mathrm{I}(1)$, we assume $-1<\rho \leq 1$, with the cases $|\rho|<1$ and $\rho=1$ corresponding to $\mathrm{I}(0)$ and $\mathrm{I}(1)$ errors, respectively. Given that we are interested in examining the PSH, the null hypothesis to be tested is $H_{0}: \beta=0$, and we wish to conduct tests on this hypothesis without assuming knowledge of whether the errors $u_{t}$ are stationary or contain a unit root.

In the context of such a DGP, Perron and Yabu (2009a) propose a test of $H_{0}: \beta=0$ that is robust to the order of integration properties of the underlying errors $u_{t}$. Their strategy is based on quasi-feasible GLS estimation of (7)-(8), i.e. a test based on $\hat{\beta}_{Q F}$, the OLS estimator of $\beta$ in the regression:

$$
p_{t}-\tilde{\rho}_{M S} p_{t-1}=\left(1-\tilde{\rho}_{M S}\right) \alpha+\beta\left[t-\tilde{\rho}_{M S}(t-1)\right]+\left(u_{t}-\tilde{\rho}_{M S} u_{t-1}\right), \quad t=2, \ldots, T
$$

together with $y_{1}=\alpha+\beta+u_{1}$. Here, $\tilde{\rho}_{M S}$ is an estimator of $\rho$ designed to be super-

\footnotetext{
${ }^{18}$ Harvey et al. (2010) suggest the value-added price deflator used by HPIM has three advantages over export unit values: first, it omits the influence of intermediate products; second, it allows for compositional changes; and third, technological progress is, to some extent, reflected in the deflator.
} 
efficient when $\rho=1$. It is obtained by first constructing a bias-corrected estimator of $\rho$ using the truncated weighted symmetric least squares method of Roy and Fuller (2001); Perron and Yabu consider two such estimators derived under different truncation settings (see their paper for full details), which we denote by $\tilde{\rho}_{M U}$ and $\tilde{\rho}_{U B}$. This bias-corrected estimate is then assigned a value of 1 when it lies within a $T^{-1 / 2}$ neighbourhood of 1 , generating the estimator $\tilde{\rho}_{M S}$, i.e.:

$$
\tilde{\rho}_{M S}= \begin{cases}\tilde{\rho}_{M} & \text { if }\left|\tilde{\rho}_{M}-1\right|>T^{-1 / 2} \\ 1 & \text { if }\left|\tilde{\rho}_{M}-1\right| \leq T^{-1 / 2}\end{cases}
$$

where $\tilde{\rho}_{M}$ denotes either $\tilde{\rho}_{M U}$ or $\tilde{\rho}_{U B}$. Finally, the robust trend test statistic is given by:

$$
t_{\beta}^{R Q F}=\frac{\hat{\beta}_{Q F}}{\sqrt{\hat{h}_{\varepsilon}\left(X^{\prime} X\right)_{22}^{-1}}}
$$

where $\left(X^{\prime} X\right)_{22}^{-1}$ denotes the $(2,2)$ element of $\left(X^{\prime} X\right)^{-1}$ with $X=\left[x_{1}, \ldots, x_{T}\right]^{\prime}, x_{t}^{\prime}=$ $\left[1-\tilde{\rho}_{M S}, t-\tilde{\rho}_{M S}(t-1)\right]$ for $t=2, \ldots, T$ and $x_{1}^{\prime}=[1,1]$, and where $\hat{h}_{\varepsilon}$ denotes the long-run variance estimator detailed in section 3 of Perron and Yabu (2009a), the exact form of which depends on whether $\tilde{\rho}_{M S}=\tilde{\rho}_{M}$ or $\tilde{\rho}_{M S}=1$. We denote the two

alternative versions by $t_{\beta}^{R Q F}(M U)$ and $t_{\beta}^{R Q F}(U B)$, according to which of $\tilde{\rho}_{M U}$ and $\tilde{\rho}_{U B}$ is used. Perron and Yabu show that these statistics both follow an asymptotic standard normal distribution under the null $H_{0}: \beta=0$.

\subsection{Testing for breaks in trend}

The extant literature has shown that relative commodity prices may not be optimally represented by a single, secular trend but by some segmented alternative (see, inter alia, Ghoshray, 2011, and Kellard and Wohar, 2006). When assessing the evidence for a broken trend, this literature has typically, as in the unbroken trend context, relied on procedures that require pre-testing for a unit root. To circumvent the issues 
surrounding the identification of the order of integration, and to examine directly whether commodity prices contain a break in trend, Harvey et al. (2010) employ the Harvey et al. (2009) test for a single break in trend, which does not assume any a priori knowledge as to the order of integration of series. Analogously, Perron and Yabu (2009b) provide a robust test for a single trend break that adopts the same broad approach as the Perron and Yabu (2009a) test for a linear trend.

Of course, it is quite possible that commodity price series contain more than one structural break, particularly given the long historical time series under consideration in this chapter, thus we next consider testing for the presence of multiple breaks in trend. We therefore augment the deterministic component of the DGP to allow for, say, $m$ breaks in level/trend, i.e. we consider replacing (7) with the following specification:

$$
p_{t}=\alpha+\beta t+\sum_{j=1}^{m} \delta_{j} D U_{j t}\left(T_{j}^{B}\right)+\sum_{j=1}^{m} \gamma_{j} D T_{j t}\left(T_{j}^{B}\right)+u_{t}, \quad t=1, \ldots, T
$$

where $D U_{j t}\left(T_{j}^{B}\right)=1\left(t>T_{j}^{B}\right)$ and $D T_{j t}\left(T_{j}^{B}\right)=1\left(t>T_{j}^{B}\right)\left(t-T_{j}^{B}\right), j=1, \ldots, m$, with 1 (.) denoting the indicator function and $T_{j}^{B}, j=1, \ldots, m$, denoting the break dates.

In this framework, Kejriwal and Perron (2010) propose a methodology for determining the number of breaks in trend, robust to the order of integration of the errors $u_{t}$, based on a sequential application of the Perron and Yabu (2009b) procedure for detecting a single break in trend. The first step is to apply the Perron and Yabu (2009b) test directly to the series, testing the null of no breaks against the alternative of one break in level/trend. As in the linear trend testing context, the Perron-Yabu approach involves a test based on quasi-feasible GLS estimation, i.e. the regression:

$$
\begin{aligned}
p_{t}-\tilde{\rho}_{M S} p_{t-1}= & \left(1-\tilde{\rho}_{M S}\right) \alpha+\beta\left[t-\tilde{\rho}_{M S}(t-1)\right]+\delta_{1}\left[D U_{1 t}\left(T_{1}^{B}\right)-\tilde{\rho}_{M S} D U_{1, t-1}\left(T_{1}^{B}\right)\right] \\
& +\gamma_{1}\left[D T_{1 t}\left(T_{1}^{B}\right)-\tilde{\rho}_{M S} D T_{1, t-1}\left(T_{1}^{B}\right)\right]+\left(u_{t}-\tilde{\rho}_{M S} u_{t-1}\right), \quad t=2, \ldots, T
\end{aligned}
$$


together with $y_{1}=\alpha+\beta+u_{1}$. As before, $\tilde{\rho}_{M S}$ is given by:

$$
\tilde{\rho}_{M S}= \begin{cases}\tilde{\rho}_{M} & \text { if }\left|\tilde{\rho}_{M}-1\right|>T^{-1 / 2} \\ 1 & \text { if }\left|\tilde{\rho}_{M}-1\right| \leq T^{-1 / 2}\end{cases}
$$

now with $\tilde{\rho}_{M}$ a bias-corrected estimator of $\rho$ based on an OLS Dickey-Fuller regression (allowing for a constant, trend and break in level/trend) and the subsequent correction of Roy and Fuller (2001) (see Perron and Yabu, 2009b, for full details). For a known break date $T_{1}^{B}$, the test statistic is an autocorrelation-corrected Wald-type statistic for testing $H_{0}: \delta_{1}=\gamma_{1}=0$, the precise form of which depends on whether $\tilde{\rho}_{M S}=\tilde{\rho}_{M}$ or $\tilde{\rho}_{M S}=1$ (see their paper for details); we denote this statistic by $W_{R Q F}\left(T_{1}^{B}\right)$. However, given that the timing of any potential break is treated as unknown, the final PerronYabu statistic is obtained by taking the following functional of the Wald-type statistics across all candidate break dates:

$$
\operatorname{Exp}-W=\log \left\{T^{-1} \sum_{T_{1}^{B} \in[\lfloor\pi T\rfloor,\lfloor(1-\pi) T\rfloor]} \exp \left[\frac{1}{2} W_{R Q F}\left(T_{1}^{B}\right)\right]\right\}
$$

where $\lfloor$.$\rfloor denotes the integer part of the argument, and the fraction 0<\pi<1$ represents a trimming parameter (set to 0.10 in this chapter) excluding breaks at the very beginning or end of the sample. Although the limit null distribution of Exp-W differs under I(0) and I(1) errors, Perron and Yabu (2009b) show that the critical values are not dissimilar at typical levels of significance, and recommend using the maximum of the $\mathrm{I}(0)$ and $\mathrm{I}(1)$ critical values to ensure the resulting test is conservative. ${ }^{19}$

If the null of zero breaks in level/trend is not rejected, the Kejriwal and Perron procedure terminates. Otherwise, the next step is to condition on there being at least one break, and proceed to examine evidence for more than one break. The sequential

\footnotetext{
${ }^{19}$ Note that in the I(1) case, normality of the innovations is assumed when obtaining the null limit distribution, due to the fact that the level change dummy variable in the GLS regression becomes an outlier when $\tilde{\rho}_{M S}=1$.
} 
procedure continues according to the following steps, beginning with $l=1$ :

1. Conditional on $l$ break(s) having been detected, estimate the timing of the break(s) $T_{1}^{B}, \ldots, T_{l}^{B}$ by minimising the global sum of squared residuals (SSR) obtained from OLS estimation of (10) across all candidate break points, i.e.:

$$
\hat{T}_{1}^{B}, \ldots, \hat{T}_{l}^{B}=\arg \min _{T_{1}^{B}, \ldots, T_{l}^{B} \in[\lfloor\pi T],\lfloor(1-\pi) T\rfloor]} \sum_{t=1}^{T} \hat{u}_{t}^{2}\left(T_{1}^{B}, \ldots, T_{l}^{B}\right)
$$

with $\hat{u}_{t}\left(T_{1}^{B}, \ldots, T_{l}^{B}\right)$ denoting the residuals in the OLS estimated equation:

$$
p_{t}=\hat{\alpha}+\hat{\beta} t+\sum_{j=1}^{l} \hat{\delta}_{j} D U_{j t}\left(T_{j}^{B}\right)+\sum_{j=1}^{l} \hat{\gamma}_{j} D T_{j t}\left(T_{j}^{B}\right)+\hat{u}_{t}\left(T_{1}^{B}, \ldots, T_{l}^{B}\right), \quad t=1, \ldots, T .
$$

2. Split the sample into $l+1$ segments according to the estimated break dates $\hat{T}_{1}^{B}, \ldots, \hat{T}_{l}^{B}$. Compute the $\operatorname{Exp}-W$ test statistic (12) for a single break in trend for each of the $l+1$ segments, denoting the resulting statistics $\operatorname{Exp}-W_{1}, \ldots, E x p-W_{l}$.

3. Test the null of $l$ break(s) against the alternative of $l+1$ breaks using the test statistic

$$
F_{T}(l+1 \mid l)=\max \left\{\operatorname{Exp}-W_{1}, \ldots, \operatorname{Exp}-W_{l}\right\}
$$

compared with critical values provided by Kejriwal and Perron. As with the Perron and Yabu (2009b) statistic, the limit critical values depend on whether the errors are $\mathrm{I}(0)$ or $\mathrm{I}(1)$ (but are quite close) and the maximum of the two critical values is used.

4. If no rejection is obtained, terminate the procedure with the inference that $l$ $\operatorname{break}(\mathrm{s})$ are present. If the null of $l$ break(s) is rejected, increase $l$ by 1 and repeat from step 1.

Although in principle this sequential procedure can continue until termination 
where no further breaks are detected, in practice Kejriwal and Perron caution against allowing too many breaks in finite samples, given the potential for size distortions and low power that can arise in the small sub-samples involved in the procedure. In our commodity price application, we set the maximal number of breaks to be three.

\section{Empirical results and discussion}

\subsection{Commodity price trend function analysis}

Table 1 shows the results of applying the order of integration robust trend test $t_{\beta}^{R Q F}(M U)$ presented in section 4.1 to the new relative commodity price indices outlined in section $3 .^{20}$ The table also reports estimated growth rates and confidence intervals based on the quasi-feasible GLS approach of Perron and Yabu (2009a), i.e. from estimation of (9). Notably, for both new series CCPI and CCPI' over the full sample, the null of no trend is rejected in favour of the alternative of a negative trend at the $1 \%$ significance level. This is a striking result, particularly when considering the sample length of the new commodity indices. The two series, commencing in 1650, have declined subsequently at an annual average rate of approximately $0.9 \%$.

On the other hand, although the three sub-sample series also display negative growth rates, only the test statistic for the GYCPI series is large enough to reject the null from 1900 onwards. The inability of the CCPI and CCPI' series to generate rejections of the null of no trend is perhaps reflective of their relatively larger variance over the course of the 20th century, compared with the GYCPI data. Note that testing against a two-sided alternative (allowing for the possibility of positive trends) does not lead to any further rejections of the no trend null.

Focusing now on the two ultra-long series (CCPI and $\mathrm{CCPI}^{\prime}$ ), it is important to

${ }^{20}$ The $t_{\beta}^{R Q F}(U B)$ test gives analogous results and is therefore not reported. Additionally, the $z_{\lambda}$ test of Harvey et al. (2007) also gives similar results that are available on request from the authors. 
next consider the possibility that one or more structural breaks have occurred in the deterministic trend function, as discussed in section 2.2. Table 2 reports results for the Kejriwal and Perron (2010) sequential order of integration robust procedure for detecting the number of breaks in level/trend, up to the maximum number permitted of three. For each step of the sequential procedure, the table reports results for the $F_{T}(l+1 \mid l)$ test of $(15)$, and, if a rejection is obtained in favour of $l+1$ break(s), the estimated break date(s) obtained at each stage using (13) are also reported. The end result of the procedure is a finding of evidence (at the $1 \%$ significance level) in favour of three breaks in level/trend for both CCPI and CCPI'. The breaks occur at the dates 1820, 1872/3 and 1946, with the corresponding fitted values at these minimum global SSR dates, i.e. the fitted values from (14), given by:

$$
\text { CCPI: } \quad \begin{aligned}
p_{t} & =2.88-0.0079 t \\
& +0.34 D U_{1 t}(1820)+0.0031 D T_{1 t}(1820) \\
& -0.37 D U_{2 t}(1872)-0.0087 D T_{2 t}(1872) \\
& +0.49 D U_{3 t}(1946)-0.0049 D T_{3 t}(1946)+\hat{u}_{t}
\end{aligned}
$$

$\mathrm{CCPI}^{\prime}: \quad p_{t}=2.88-0.0079 t$

$$
\begin{aligned}
& +0.34 D U_{1 t}(1820)+0.0027 D T_{1 t}(1820) \\
& -0.39 D U_{2 t}(1873)-0.0074 D T_{2 t}(1873) \\
& +0.68 D U_{3 t}(1946)-0.0059 D T_{3 t}(1946)+\hat{u}_{t}
\end{aligned}
$$

Graphical representations of these results are given in Figures 4 and 5 .

The two commodity price indices can therefore be approximately split into four intertemporal regimes: 1650 to the early 1820s; the early 1820 s to the early $1870 \mathrm{~s}$; the early 1870s to the mid-1940s; and the mid-1940s to the present day. To ascertain 
whether the trends in each of these four regimes are significantly negative, we wish to test the following hypotheses (based on the model (10)): $H_{0}: \beta=0$ for the first regime (1650-1820), $H_{0}: \beta+\gamma_{1}=0$ for the second regime (1821-1872/3), $H_{0}: \beta+\gamma_{1}+\gamma_{2}=0$ for the third regime (1873/4-1946), and $H_{0}: \beta+\gamma_{1}+\gamma_{2}+\gamma_{3}=0$ for the fourth regime (19472010), in each case against a one-sided (lower-tailed) alternative. In order to conduct tests of these hypotheses that are again robust to the order of integration of the errors, we consider a quasi-feasible GLS-based testing approach consistent with the Perron and Yabu (2009b) approach for testing for a break. Specifically, conditioning on the three dates determined by the Kejriwal and Perron (2010) procedure, we use autocorrelationcorrected $t$-tests based on quasi-feasible GLS estimation of (10), with quasi-difference parameter $\tilde{\rho}_{M S}$ as defined in (11), but with $\tilde{\rho}_{M}$ now a bias-corrected estimator of $\rho$ based on an OLS Dickey-Fuller regression that allows for a constant, trend and the three breaks in level/trend. The resulting autocorrelation-corrected $t$-statistics are then formed in an analogous way to $W_{R Q F}\left(T_{1}^{B}\right)$ of Perron and Yabu (2009b), and, conditional on the break dates, follow asymptotic standard normal distributions under the respective null hypotheses. Table 3 reports the results, and we find strong evidence in favour of a declining trend in all regimes for $\mathrm{CCPI}^{\prime}$, and for CCPI, all regimes apart from 1821-1872, where the trend estimate is negative but found to be insignificantly different from zero.

The vast majority of work has examined the PS hypothesis over the post-1900 period but we can now additionally comment on its relevance prior to the 20th century. Strikingly, our results confirm that relative commodity prices present a significant and downward global trend over almost the entire sample period. With the exception of the 1821-1872 period, the growth rates of the commodity price indices were found to decline in the ranges $-0.79 \%$ to $-1.83 \%$ per annum for CCPI, and $-0.79 \%$ to $-1.84 \%$ per annum for $\mathrm{CCPI}^{\prime}$, over the different regimes. It is noticeable that the broadly declining trend paths of the price series are punctuated by structural breaks in the 
level and trend; 1820 shows a sharp rise in the level and trend, 1872/3 sees a sharp fall in level and trend, while 1946 shows a rise in level but further decline in trend ${ }^{21}$. This identification of changing trend behaviour provides new characterisations of historical price behaviour - for example, the 19th century terms of trade boom is captured by a local increase in prices during the second regime (i.e. early 1820s to the early 1870s), superimposed on a generic long-run downward trend. Moreover, the results suggest that the decline in trend has been greater since the early 1870s than at any time previous (albeit offset to some extent by an upward level shift in 1946). The causes behind the modern incarnation of the PS hypothesis therefore appear arguably stronger than those that existed in the more distant past - we shall return to this later.

\subsection{Economic history and time series analysis}

Earlier in the chapter, we suggested that the time series characteristics of aggregate commodity series might be usefully cross-referenced with the extant economic history literature to provide futher insights into the causal underpinnings of long-run price movements. Considering first the 17th and 18th centuries, our results show the growth rate of the commodity price indices declining significantly between 1650 and the early 1800 s at approximately $0.79 \%$ per annum. It is important to note that traded goods for the three centuries (i.e., 16th, 17th, 18th) following the exploratory voyages of Columbus (1451-1506) and da Gama (1460/1469-1524) were typically non-competing, high priced luxury goods (i.e., spices, sugar and gold), worth transporting over large distances at high cost (see O'Rourke and Williamson, 2002 and 2004). Subsequently, trade in the 19th and 20th century is characterised by increasingly lower priced goods. The trade boom (from the early 1500s to late 1700s) was therefore driven by discovery and growing demand in Europe; however, prices were supported by duties, monopolies and the high cost of sea transportation (including piracy) which did not begin to fall

\footnotetext{
${ }^{21}$ Sumner (2009) notes that agricultural commodity prices rose sharply through World War II to post-war spikes.
} 
until the 19th century (see O'Rourke and Williamson, 2002).

Perhaps the most important traded commodity in the 17th and 18th centuries was sugar. The great naval powers of the time (i.e. Spain, Portugal and Britain) imported sugar from West Indian and South American colonies, devoting enormous resources to protecting the trade. ${ }^{22}$ European consumption grew astonishingly; for example, from 1663 to 1775, consumption in England and Wales increased twenty fold (Robbins, 1999). As the demand for sugar grew, supply was encouraged, and although the price was supported by the factors discussed above, prices fell and sugar consumption became no longer the preserve of the upper classes (see Robbins, 1999). Given the dominant role of sugar in the commodity indices prior to the 19th century, it is plausible to view the gradual decline of the indices as reflecting that of sugar until the occurrence of the commodity supply disruptions brought about by the combined efforts of the American War of Independence, the French Revolution and the Napoleonic Wars from 1776-1812 (see O’Rourke, 2006).

Moving on, our results in the previous subsection show a relative boom in relative commodity prices between the early 1820s and the early 1870s. Analogously, Williamson (2008) posits that a terms of trade boom for commodity exporting countries occurred during the 19th century and encouraged primary commodity specialisation in the poor periphery. The boom itself can perhaps be attributed to three primary factors noted by Williamson (2008): growing GDP in the industrialising European core, liberalisation of trade, and the rapid fall in transport costs via sea (see Jacks and Pendakur, 2010) and rail routes. In particular, the relative technology improvements in manufacturing compared to other economic activities (see Clark et al., 2008), occurring while demand in the core for commodities rose, produced upward pressure on the periphery terms of trade. The resulting specialisation is hypothesised by Williamson

\footnotetext{
${ }^{22}$ It should not go without comment that the sugar trade was a major factor in the expansion of the Atlantic slave trade. As Robbins (1999, p.216) notes, "From 1701 to 1810 almost one million slaves were brought to Barbados and Jamaica to work on the sugar plantations".
} 
(2008) to have caused deindustrialisation ${ }^{23}$ via the twin mechanisms of high commodity price levels and the associated volatility ${ }^{24}$, and ultimately the Great Divergence, as the income gap between the industrial core and poor periphery widened.

Earlier seminal work by Lewis $(1978 \mathrm{a}, 1978 \mathrm{~b})$ proposed the causal factors for the Great Divergence operated primarily between 1870 and 1913. In contrast, Williamson (2008) suggests the relevant period can be dated before and up to 1870. Our results provide new statistical evidence for the latter claim. Given relative commodity prices are an appropriate proxy for periphery terms of trade, the early 1820 s to the early 1870 s period is clearly a hiatus in the falling terms of trade experienced in the centuries before. Indeed, Figure 1 shows a long boom from around 1820 to the mid-1840s and a local peak during the mid-1860s. If any period could incentivise commodity price specialisation and resulting deindustrialisation, it seems plausible to suggest the globalisation phase in the 19th century prior to 1870.

Our statistical work shows that after 1870 , the trend in relative commodity prices fell at a faster rate than before 1800. In part, this is because the technological differential between manufacturing and primary commodity production narrows over the 20th century. Additionally, the continued and rising economic growth in the industrialising core (despite two world wars) drove the formation of large oligopolistic manufacturing firms at a global scale. However, the deindustrialisation or non-industrialisation in primary commodity producing nations, has resulted in relatively small, homogeneous producers compensating workers with low wages. It is perhaps the joint application of these forces - technological differentials, larger oligopolistic manufacturing firms, non-

\footnotetext{
${ }^{23}$ We suggest an appropriate term in some country cases might be "non-industrialisation".

${ }^{24}$ Recent research has established a link between commodity price volatility, lower growth and disincentives to invest in countries with economies dominated by natural resource production (see, inter alia, Poelhekke and van der Ploeg, 2009). Additionally, as Jacks et al. (2009, p.5) note, “...while greater volatility increases the need for international borrowing to help smooth domestic consumption, Catão and Kapur (2004) have shown recently that volatility constrained the ability to borrow between 1970 and 2001. It seems likely that the same was true between 1870 and 1901, a century earlier, and even more so before 1870 when a global capital market was only just emerging (Obstfeld and Taylor 2004; Mauro et al. 2006)".
} 
industrialisation of the periphery, low wages and continued poverty in the periphery, that have caused such downward pressure on relative commodity prices over the course of the 20th century.

Finally, it should be noted that although our time series analysis indicates a signifcant, downward trend over several centuries, at the end of our sample period we faced a relative upturn in commodity prices in the early 21st century. Are there parallels in the past to inform the future behaviour of these prices? One might suggest that the 19th century boom is perhaps analogous to the situation in the early 21 st century, as China, India and other emerging nations industrialise, demand more primary commodities and increase their relative price. Assuming the underlying drivers of modernisation in the developing world are likely to remain in place, the 19th century experience shows that real commodity prices can remain above trend for many years before reverting to secular decline. Given recent falls in nominal commodity prices during 2014, we are perhaps witnessing some reversion currently.

\subsection{GDP trend function analysis}

In section 2, it was suggested that a useful proxy for the factors affecting the trend in relative commodity prices might be the trend growth rate of economic activity. In particular, we conjectured that common trend breaks in commodity prices and relevant GDP series would provide some evidence for this idea. Therefore, to investigate and for consistency, we apply the same trend tests (here against a positive trend alternative) and trend break tests to historical GDP series for the UK, World and China.

The UK became the world's pre-eminent economy over the course of the 17th to 19th century and by the early 1800s had the highest per capita income in the world (see Bolt and Van Zenden, 2013). We initially source our income data, similarly to Erten and Ocampo (2013), from Angus Maddison's data, updated recently by the 
Maddison Project. ${ }^{25}$ However, this annual data for UK GDP only goes back to 1800. Recently, Broadberry et al. (2011) produced a real output series for the UK from 1270 to 1870 . It is this data from 1650 that is plotted in Figure 6 and the results of the trend and trend break tests shown in the top sections of Tables 4 and 5 respectively. ${ }^{26}$ Interestingly, UK GDP shows a significant and positive trend growth rate of $1.28 \%$ per annum over the sample period, helping to explain the increasing demand for luxury goods like sugar and providing the downward pressure on real commodity prices until the early 19th century. Moreover, a positive break in the trend in 1817, capturing the UK's rising industrial production, technological advances in manufacturing and growth, closely matches the first break found in our CCPI series and the terms of trade boom for the periphery dated in the previous section.

The US overtook the UK in terms of GDP in the 1870s (see Broadberry and Klein, 2011) and the rest of the industrial core also grew strongly over much of the 19th and 20th century. This is reflected in the growth of World GDP ${ }^{27}$ plotted in Figure 7 for 1820-2009. Table 4 shows the trend presents a growth rate of $2.23 \%$ per annum whilst Table 5 shows breaks of a positive sign occur in the trend during the 1870s and 1950s. ${ }^{28}$ Again, these breaks closely match those identified for earlier CCPI series. Overall, it would appear that since the 1870s, increasing rates of trend economic growth in World GDP are associated with declining trend rates in relative commodity prices. This provides further support for the idea that some of the characteristics of industrial core growth (e.g., the tendency to oligopoly) coupled with the over-specialisation of periphery nations into primary commodity exports, led to declining commodity prices, inhibiting periphery growth and enhancing the Great Divergence.

\footnotetext{
${ }^{25}$ See http://www.ggdc.net/maddison/maddison-project/home.htm

${ }^{26}$ Given the shorter sample period available for the UK GDP series, we set the maximal number of breaks to two.

${ }^{27}$ The source for this data is also the Maddison Project. Similarly to Erten and Ocampo (2013) we use the annual GDP series for the World with complete data from 1950 onwards and discrete values for 1820, 1870, 1913 and 1940. The missing values are interpolated using data for 16 OECD countries from 1870, and the 7 available OECD countries from 1820.

${ }^{28} \mathrm{As}$ for the UK GDP series, here we set the maximal number of breaks to two.
} 
In any case, it is useful to estimate (6) to get a sense of the association between economic activity and relative commodity prices. Assuming (6) represents some very long-run stable (e.g. cointegrating) relationship, we can estimate the following regression using FM-OLS for 1650-2009: ${ }^{29}$

$$
p_{t}=4.28-0.430 y_{t}+\hat{u}_{t}
$$

where $p_{t}$ denotes the logarithms of CCPI' (results for CCPI were very similar). Notably, tests of cointegration including Phillips-Ouliaris ( $\tau$ statistic is -4.01 with a p-value of 0.008 ) and Engle-Granger ( $\tau$ statistic is -4.16 with a p-value of 0.005 ) reject the null of no-cointegration ${ }^{30}$. Given our estimate of $\lambda$ is -0.430 , this implies that for every one percent increase in economic activity, there is a 0.43 percent decline in long-run relative commodity prices. Figure 8 represents this graphically, showing the actual and fitted values from (16). In particular, the post-1870s period has clearly not been a supportive or even benign period for commodity-dependent developing countries. Work such as Sachs and Warner (1995, 1997, 2001) and Van der Ploeg and Poelhekke (2009) provide evidence documenting the negative relationship between commodity dependence and economic growth - the so-called resource curse. Our analysis, showing a strong negative relationship between long-run relative commodity prices and long-run economic growth provides further evidence to support this notion and suggests that falling prices and their attendant wealth effects, have been an important channel by which the resource curse has operated.

Of course, since the mid-1990s and over most of the first decade of the 21st century, commodity prices rose (see Figures 1 and 2). Academics (see, for example, Cuddington and Jerrett, 2008) and commentators alike asked whether prices were in a positive

\footnotetext{
${ }^{29}$ To create a commodity-relevant economic activity series from 1650 we combine the real UK GDP series from Broadberry et al. (2011) from 1650-1870 with the Maddison World GDP data 1870-2009, using the common year 1870 to convert the data into a unified series.

${ }^{30}$ Erten and Ocampo (2013) also showed that economic activity and commodity prices are cointegrated.
} 
growth phase of a super-cycle; a medium-length cyclical movement with a periodicty between 20 and 40 years. As we noted in the previous section, explanations for higher prices include the rapid economic growth delivered by China and other modernising developing economies. Figure 9 plots the available Maddison GDP data for China from 1950 and Tables 4 and 5 show the trend and trend break tests. ${ }^{31}$ Interestingly, China's path of trend growth broke positively around the late 1970s and has since shown particularly high growth rates of $7.5 \%$ per annum. If this continued, real commodity prices could remain supported above trend (similar to the mid-19th century) for a number of years. However, as noted in the previous sub-section, recent price falls occurred during 2014 and are associated with falling oil prices and concerns around the future economic growth of countries like China. To assess the length of any possible cycle, we next apply a recent filtering procedure to the aggregate commodity prices series over the full sample (1650-2010) and some relevant sub-samples.

\subsection{Analysis of cyclical components}

Recent work such as Erten and Ocampo (2013), Harvey et al. (2010) and Cuddington and Jerrett (2008) have employed the asymmetric band pass filter of Christiano and Fitzgerald (2003) to partition commodity price series into three components:

$$
p_{t}=T_{t}+L C_{t}+S C_{t}, \quad t=1, \ldots, T
$$

where $T_{t}$ is a trend component, $L C_{t}$ is a long-term cyclical component and $S C_{t}$ a short-term cyclical component. Christiano and Fitzgerald (2003) introduce a filter that develops the band pass approach of Baxter and King (1999) and allows the three cyclical components to be computed without trimming the end-points of the data sample. The filter can be implemented whether the time series presents a unit root or

\footnotetext{
${ }^{31}$ As the China series only contains 61 observations, we set the maximal number of breaks in this series to one.
} 
is stationary (around a deterministic component).

Following Cuddington and Jerrett (2008), the trend is defined as all cyclical components lasting 70 years or longer. Long-term cycles are then defined as lasting from 20-70 years and short-term cycles as ranging from 2-20 years. Denoting by $C F\left(c_{1}, c_{2}\right)$ the asymmetric band pass filter that passes cycles between $c_{1}$ and $c_{2}$ in length, we can define $T_{t}, L C_{t}$ and $S C_{t}$ as follows:

$$
\begin{aligned}
T_{t} & =C F(70, \infty) \\
L C_{t} & =C F(20,70) \\
S C_{t} & =C F(2,20) .
\end{aligned}
$$

The initial step of the Christiano and Fitzgerald filter is to de-trend the data under the assumption that a unit root is present in the data. In an unbroken trend framework, the estimate of $\beta$ in (7)-(8) is therefore obtained by OLS estimation with $\rho$ set to 1 , i.e. OLS estimation of the first differenced regression $\Delta y_{t}=\beta+\varepsilon_{t}$. If breaks in the trend function are detected, this initial step can be modified by including the breaks in the deterministic component used for the de-trending, now estimating the relevant coefficients using a first differenced version of (10).

Table 6 provides summary measures of the cyclical components. The sub-samples considered are primarily based around the estimated break dates identified in the earlier part of the empirical results, while also ensuring that each sub-sample is of a suitable length for estimating long-term cycles; specifically, we consider 1650-1872/3 and 1872/3-2010. Additionally, the period 1900-2010 is examined, given that a starting value of 1900 is consonant with the common initial date used in the extant literature. The deterministic component used to de-trend the data in each sample employs the estimated break dates identified in section 4.2. A graphical representation of the full sample cyclical components is given in Figures 10 and 11. 
Column 2 of Table 6 shows the standard deviation of the long-term cyclical component $L C_{t}$, and column 4 shows the ratio of the standard deviations of $L C_{t}$ and the total non-trend cyclical component $S C_{t}+L C_{t}$. The range of this ratio extends from 0.709 to 0.895 and, analogously to Harvey et al. (2010), indicates the primacy of the long-term component in cyclical commodity price movements. The mean periodicity of the $L C_{t}$ cycles (see column 5) ranges from 26.571 years to 31.500 years and appears to get longer as the sample moves into the 20th century. This increasing periodicity, accompanied by an increasing standard deviation, is further suggestive of the increasing amplitude that can be observed in Figures 10 and 11. Clearly, if long-term cycles are increasing both in amplitude and duration, policy initiatives to directly smooth commodity prices or producer or consumer incomes around a trend will require economic planning over increasingly long time horizons.

Conversely, the mean periodicity of the $S C_{t}$ cycles (see column 6) ranges from 3.815 years to 4.255 years and appears to get shorter as the sample moves into and through the 20th century. Indeed, although we consider the 1947-2010 period to be too short to reliably estimate long-term cycles, we additionally computed estimates of the short-run cyclical components over this most recent sub-sample; interestingly, the mean periodicity of the $S C_{t}$ cycles falls further to 3.529 years and 3.867 years for CCPI and $\mathrm{CCPI}^{\prime}$, respectively. This is suggestive of increasing commodity price volatility, analogous to the results of Cashin and McDermott (2002), but placed in the context of a much longer time period. Given the literature has established an empirical link between volatility and growth, the observed increase in volatility is likely to have been damaging to investment and growth in poorer commodity-dependent countries.

Finally, even with super-cycles lasting around 31 years, from our prior analysis the lesson of the past four centuries appears to be that a negative trend in relative commodity prices eventually re-asserts itself. When forecasting over the long-run and deciding on whether to treat commodity-export income as permanent or temporary, 
policy makers should bear this uppermost in mind.

\section{Conclusions}

Many developing countries present export earnings that are primary commodity dependent. Therefore, the presence of a secular decline in primary commodity relative prices as implied by the Prebisch-Singer hypothesis, suggests that unless developing countries diversify into manufactures and/or services, they will incur long-run economic stagnation. However, as Deaton and Laroque (2003) note, despite a large literature attempting the estimation of a trend, our understanding of any causes of the long-run path in relative commodity prices is relatively limited. In particular, any causal investigation of the trend is hampered by the lack of historical data on possible factors such as income elasticities of demand, technological and productivity differentials, and relative market power measures between the core (industrial) and periphery (non-industrial and commodity exporting) countries. We suggest a threefold approach to circumvent the lack of data.

First, we argue that aggregating relative commodity prices over the very longrun can smooth idiosyncratic effects and provide summary series shaped primarily by common factors. To this end, this chapter constructs new aggregate real commodity price series from 1650 to 2010. The series are created by combining a new historical dataset on the export values of 23 commodities, with the individual commodity price dataset from Harvey et al. (2010). Subsequently, employing multiple break techniques robust to whether or not each series contains a unit root, it is shown that the trend path of these series can be partitioned into four regimes (i.e. 1650 to the early 1820s, the early 1820 s to the early 1870 s, the early 1870 s to the mid-1940s, and the mid1940s to 2010). A long-run downward trend is estimated in all but the second regime, revealing that the Prebisch-Singer hypothesis has relevance for the 17th, 18th and 20th 
centuries at least. However, it is also shown that the series declined at a slower rate over the 17th and 18th centuries as compared with the 20th century, suggesting that the economic forces underlying the hypothesis intensified over this recent period.

Secondly, we suggest that the new time series understanding can help clarify some of the latent factors behind the trend. For example, from 1650 to the early $1820 \mathrm{~s}$ was a period of modest economic growth, particularly in the UK. This growth provided the demand for high-priced luxury goods like sugar and increasing supply from the Caribbean allowed real prices to fall. By contrast, the 1820s to 1870s presented stronger economic growth throughout the industrialising core. This increased demand for primary commodities, allied to technological advances in manufacturing, saw a terms of trade boom in the commodity-exporting periphery. However, our dating provides further evidence for the claims of Williamson (2008) that the periphery became over-reliant on commodities at this time leading to local deindustrialisation. This is key in understanding the larger decline in trend commodity prices post 1870 and throughout most of the 20th century. Specifically, as the industrial core continued to grow, oligopolistic manufacturing firms with market power at a global level pushed prices lower as they interacted with far smaller, homogeneous primary commodity firms with large supplies of labour at, or close to, the subsistence wage.

Thirdly, we posit that the trend growth rate of economic activity, data that is available over an historical timeframe, is a useful proxy for the factors underlying the trend in relative commodity prices. To this end, it is shown that breaks in the trend growth rate of UK and World GDP are commensurate with those in the trend of commodity prices. Moreover, a negative relationship between trends in commodity prices and economic activity is estimated. For example, over our full sample, as World GDP grew by one percent, the relative commodity prices fell by 0.43 percent. This association helps explain the Great Divergence between the periphery and industrial core over the 20th century, linking it closely to the resource curse. 
Finally, we note that although commodity prices were relatively high (compared to trend) at the end of our sample, and even with super-cycles lasting around 31 years, the empirical evidence in this chapter suggests that prices eventually revert to a negative trend. Therefore, policymakers should be careful not to treat commodity-export income as permanent. For example, a univariate time series model estimated using our data would continue to forecast a negative trend over an infinite horizon. However, the above explantion of the causal underpinnings of the trend suggests that this secular decline might not continue indefinitely. The falling trend in real commodity prices since 1870 appears to be conditioned on an approximate separation between an industrial core that imports primary commodities and a non-industrialised poor periphery that supplies them. If recent developing country growth in China, India, Brazil, Africa and elsewhere is used by policymakers to create permanently diversified economies, with rising real wages and some global market power, then higher, relative commodity prices could be supported over the future long-run.

\section{References}

Ardeni, P.G., Wright, B., 1992. The Prebisch-Singer Hypothesis: A Reappraisal Independent of Stationary Hypotheses. Economic Journal 102, 803-812.

Arezki, R., Loungani, P., van der Ploeg, R., Venables, A.J., 2014a. Understanding International Commodity Price Fluctuations. Journal of International Money and Finance 42, 1-8.

Arezki, R., Hadri, K., Loungani, P., Rao, Y., 2014b. Testing the Prebisch-Singer Hypothesis since 1650: Evidence from Panel Techniques that Allow for Mulitple Breaks. Journal of International Money and Finance 42, 208-223.

Badillo, D., Labys, Wu, Y., 1999. Identifying Trends and Breaks in Primary Com- 
modity Prices. The European Journal of Finance 5, 315-330.

Bairoch, P., Etemad, B., 1985. Commodity Structure in Third World Exports 18301937. Geneva: Librairie Droz.

Balagtas, J., Holt, M.T. 2009. The Commodity Terms of Trade, Unit roots and Nonlinear Alternatives: A Smooth Transition Approach. American Journal of Agricultural Economics 91, 87-105.

Baxter, M., King, R.G., 1999. Measuring Business Cycles: Approximate Band-Pass Filters for Economic Time Series. Review of Economics and Statistics 81, 575593.

Bezanson, A., Gray, R.D., Hussey, M., 1936. Wholesale Prices in Philadelphia 17841861. Philadelphia: University of Pennsylvania Press.

Beveridge, S., Nelson, C.R., 1981. A New Approach to the Decomposition of Economic Time Series into Permanent and Transitory Components with Particular Attention to Measurement of the "Business Cycle". Journal of Monetary Economics 7, 151-174.

Blattman, C., Hwang, J., Williamson, J.G., 2007. Winners and Losers in the Commodity Lottery: The Impact of Terms of Trade Growth and Volatility in the Periphery 1870-1939. Journal of Development Economics 82, 156-179.

Bolt, J., van Zenden, J.L, 2013.The First Update of the Maddison Project: ReEstimating Growth Before 1820. Maddison-Project Working Paper WP-4.

Broadberry, S.N., Campbell, B.N., Klein, A., Overton, M., van Leeuwen, B. 2011. British Economic Growth, 1270-1870: An Output-Based Approach. Department of Economics, University of Kent, Working Paper Series Studies in Economics No.1203. 
Broadberry, S.N., Klein, A., 2012. Aggregate and Per Capita GDP in Europe, 18702000: Continental, Regional and National Data with Changing Boundaries. Scandinavian Economic History Review 60, 79-107.

Catão, L., Kapur, S., 2004. Missing Link: Volatility and the Debt Intolerance Paradox. International Monetary Fund, Washington, D.C.

Cashin, P., McDermott, C.J., 2002. The Long-Run Behaviour of Commodity Prices: Small Trends and Big Variability. IMF Staff Papers 49, 175-199.

Christiano, L., Fitzgerald, T.J., 2003. The Bandpass Filter. International Economic Review 44, 435-465.

Clark., G., O’Rourke, K.H., Taylor, A.M., 2008. Made in America? The New World, the Old, and the Industrial Revolution. American Economic Review 98, 523-528.

Collier, P., van der Ploeg, F., Spence, M. and Venables, A.J., 2010. Managing Resource Revenues in Developing Economies. IMF Staff Papers 5, 84-118.

Cuddington, J., 1992. Long-Run Trends in 26 Primary Commodity Prices: A Disaggregated Look at the Prebisch-Singer Hypothesis. Journal of Development Economics 39, 207-227.

Cuddington, J. and Jerrett, D., 2008. Super Cycles in Metals Prices? IMF Staff Papers 55, 541-565.

Cuddington, J., Liang, H., 2003. Commodity Price Volatility Across Exchange Rate Regimes. Working Paper, Department of Economics, Georgetown University.

Cuddington, J., Ludema, R., Jayasuriya, S., 2007. Prebisch-Singer Redux. In: Lederman, D., Maloney, W. (Eds.), Natural Resources and Development: Are They a Curse? Are They Destiny? Stanford University Press. 
Cuddington, J., Urzua, C., 1989. Trends and Cycles in the Net Barter Terms of Trade: A New Approach. Economic Journal 99, 426-442.

Deaton, A. 1999. Commodity Prices and Growth in Africa. Journal of Economic Perspectives 13, 23-40.

Deaton, A., Laroque, G., 2003. A Model of Commodity Prices after Sir Arthur Lewis. Journal of Development Economics 71, 289-310.

Elliott, G., Rothenberg, T.J., Stock, J.H., 1996. Efficient Tests for an Autoregressive Unit Root. Econometrica 64, 813-836.

Erten, B., Ocampo, J.A., 2013. Super Cycles of Commodity Prices Since the MidNineteenth Century. World Development 44, 14-30.

Frankel, J., 2011. A Solution to Fiscal Procyclicality: The Structural Budget Institutions Pioneered by Chile. Central Bank of Chile Working Paper No. 604 .

Ghoshray, A., 2011. A Reexamination of Trends in Primary Commodity Prices. Journal of Development Economics 95, 242-251.

Greenaway, D., Morgan, C.W. (Eds.), 1999. The Economics of Commodity Markets. Aldershot: Edward Elgar.

Grilli, R.E., Yang, M.C. 1988. Commodity Prices, Manufactured Goods Prices, and the Terms of Trade of Developing Countries. World Bank Economic Review 2, $1-48$.

Harvey, D.I., Kellard, N.M., Madsen, J.B., Wohar, M.E. 2010. The Prebisch-Singer Hypothesis: Four Centuries of Evidence. Review of Economics and Statistics 92, 367-377. 
Harvey, D.I., Kellard, N.M., Madsen, J.B., Wohar, M.E. 2012. Erratum: The PrebischSinger Hypothesis: Four Centuries of Evidence. Available at SSRN: http://ssrn. com/abstract $=2202900$.

Harvey, D.I., Leybourne, S.J., Taylor, A.M.R., 2007. A Simple, Robust and Powerful Test of the Trend Hypothesis. Journal of Econometrics 141, 1302-1330.

Harvey, D.I., Leybourne, S.J., Taylor, A.M.R., 2009. Simple, Robust and Powerful Tests of the Breaking Trend Hypothesis. Econometric Theory 25, 995-1029.

Jacks, D.S., O’Rourke, K.H., Williamson, J.G., 2009. Commodity Price Volatility and World Market Integration. NBER Working Paper No. 14748.

Jacks, D.S., O'Rourke, K.H., Williamson, J.G., 2011. Commodity Price Volatility and World Market Integration. Review of Economics and Statistics 93, 800-813.

Jacks, D.S., Pendakur, K. 2010. Global Trade and the Maritime Transport Revolution. Review of Economics and Statistics 92, 745-755.

Kejriwal, M., Perron, P., 2010. A Sequential Procedure to Determine the Number of Breaks in Trend with an Integrated or Stationary Noise Component. Journal of Time Series Analysis 31, 305-332.

Kellard, N., Wohar, M.E., 2006. On the Prevalence of Trends in Primary Commodity Prices. Journal of Development Economics 79, 146-167.

Kim, T., Pfaffenzeller, S., Rayner, A., Newbold, P. 2003. Testing for Linear Trend, with Application to Relative Primary Commodity Prices. Journal of Time Series Analysis 24, 539-551.

Kondratieff, N.D, 1935. The Long Waves in Economic Life. Review of Economics and Statistics 17, 105-115. 
Kwiatkowski, D., Phillips, P.C.B., Schmidt, P., Shin, Y., 1992. Testing the Null Hypothesis of Stationarity Against the Alternative of a Unit Root: How Sure are we that Economic Time Series Have a Unit Root? Journal of Econometrics 54, 159-178.

Leon, J., Soto, R., 1997. Structural Breaks and Long-Run Trends in Commodity Prices. Journal of International Development 9, 347-366.

Lewis, W.A., 1954. Economic Development with Unlimited Supplies of Labour. Manchester School 22, 139-191.

Lewis, W.A., 1978a. The Evolution of the International Economic Order. Princeton: Princeton University Press.

Lewis, W.A., 1978b. Growth and Fluctuations, 1870-1913. Boston: Allen and Unwin.

Lima, G. T., 2000. Market concentration and technological innovation in a dynamic model of growth and distribution. Quarterly Review - Banca Nazionale del Lavoro $53,447-475$.

Mauro, P., Sussman, N., Yafeh, Y., 2006. Emerging Markets, Sovereign Debt, and International Financial Integration: 1870-1913 and Today. Oxford: Oxford University Press.

Miller, G., Urdinola, B.P., 2010. Cyclicality, Mortality, and the Value of Time: The Case of Coffee Price Fluctuations and Child Survival in Colombia. Journal of Political Economy 118, 113-155.

Newbold, P., Rayner, A.J., Kellard, N.M., 2000. Long-Run Drift, Comovement, and Persistence in Real Wheat and Maize Prices. Journal of Agricultural Economics $51,106-121$. 
Ng, S., Perron, P., 2001. Lag Length Selection and the Construction of Unit Root Tests with Good Size and Power. Econometrica 69, 1519-1554.

Obstfeld, M., Taylor, A.M., 2004. Global Capital Markets: Integration, Crisis, and Growth. Cambridge: Cambridge University Press.

O'Rourke, K.H., 2006. The Worldwide Economic Impact of the French Revolutionary and Napoleonic Wars, 1793-1815. Journal of Global History 1, 123-149.

O'Rourke, K.H., Williamson, J.G., 2002. After Columbus: Explaining the Global Trade Boom, 1500-1800. Journal of Economic History 62, 417-456.

O’Rourke, K.H., Williamson, J.G., 2004. Once More: When did Globalisation Begin? European Review of Economic History 8, 109-117.

Perron, P. and Yabu, T., 2009a. Estimating Deterministic Trends with an Integrated or Stationary Noise Component. Journal of Econometrics 151, 56-69.

Perron, P. and Yabu, T., 2009b. Testing for Shifts in Trend With an Integrated or Stationary Noise Component. Journal of Business and Economic Statistics 27, 369-396.

Poelhekke, S., van der Ploeg, R., 2009. Volatility and the Natural Resource Curse. Oxford Economic Papers 61, 727-760.

Pongou, R., Salomon, A., Ezzati, M., 2006. Health Impacts of Macroeconomic Crises and Policies: Determinants of Variation in Childhood Malnutrition Trends in Cameroon. International Journal of Epidemiology 35, 648-656.

Powell, A., 1991. Commodity and Developing Countries Terms of Trade: What does the Long-Run Show? Economic Journal 101, 1485-1496.

Prebisch, R., 1950. The Economic Development of Latin America and its Principal Problems. Economic Bulletin for Latin America 7, 1-12. 
Reinhart, C., Wickham, P., 1994. Commodity Prices: Cyclical Weakness or Secular Decline? IMF Staff Papers 41, 175-213.

Robbins, R.H., 1999. Global Problems and the Culture of Capitalism. Allyn and Bacon.

Roy, A., Fuller, A.R, 2001. Estimation for Autoregressive Processes with a Root Near One. Journal of Business and Economic Statistics 19, 482-493.

Sachs, J. D., McArthur, J. W., 2002. Technological Advance and Long-Term Economic Growth in Asia. In: Chong-En Bai, Chi-Wa Yuen (Eds.), Technology and the New Economy. Cambridge, MA: MIT Press, pp. 157-185.

Sachs, J. D., Warner, A. M., 1995. Natural Resource Abundance and Economic Growth. National Bureau of Economic Research Working Paper 5398.

Sachs, J. D., Warner, A. M., 1997. Fundamental Sources of Long-run Growth. American Economic Review, 87(2), 184-188.

Sachs, J. D., Warner, A. M., 2001. The Curse of Natural Resources. European Economic Review 45(4), 827-838.

Sapsford, D., 1985. The Statistical Debate on the Net Terms of Trade Between Primary Commodities and Manufacturers: A Comment and Some Additional Evidence. Economic Journal 95, 781-788.

Sapsford, D.P., Sarkar, P., Singer, H.W., 1992. The Prebisch-Singer Terms of Trade Controversy Revisited. Journal of International Development 4, 315-332.

Singer, H., 1950. The Distribution of Gains Between Investing and Borrowing Countries. American Economic Review (Papers and Proceedings) 40, 473-485.

Spraos, J., 1980. The Statistical Debate on the Net Barter Terms of Trade. Economic Journal 90, 107-128. 
Sumner, D.A., 2009. Recent Commodity Price Movements in Historical Perspective. American Journal of Agricultural Economics 91, 1250-1256.

Thirwall, A.P., Bergevin, J., 1985. Trends, Cycles, and Asymmetry in Terms of Trade. World Development 13, 805-817.

United Nations, 2010. Millennium Development Goals Report.

Van der Ploeg, F., Poelhekke, S., 2009. Volatility and the Natural Resource Curse. Oxford Economic Papers 61 (4), 727-760.

van der Ploeg, R., Venables, A.J., 2011. Harnessing Windfall Revenues: Optimal Policies for Resource-Rich Developing Economies. Economic Journal 121, 1-30.

Williamson, J.G., 2008. Globalization and the Great Divergence: Terms of Trade Booms, Volatility and the Poor Periphery, 1782-1913. European Review of Economic History 12, 355-391.

Yamada, H., Yoon, G., 2014. When Grilli and Yang meet Prebisch and Singer. Piecewise Linear Trends in Primary Commodity Prices. Journal of International Money and Finance 42, 193-207.

Zanias, G., 2005. Testing for Trends in the Terms of Trade Between Primary Commodities and Manufactured Goods. Journal of Development Economics 78, 49-59.

\section{Data Appendix}

The weighted average commodity price indices are constructed using export values from developing countries as weights, over the period 1830-2006. The sources used are as follows: 
1. 1830-1937. Principal source (for commodities Banana, Beef, Cocoa, Coffee, Cotton, Hides, Jute, Oil, Pig Iron, Sugar, Tea, Tobacco, Wheat and Wool): Commodity Structure of Third World Exports 1830-1937, Paul Bairoch and Bouda Etemad, Centre of International Economic History, University of Geneva.

2. 1830-1937. Secondary sources (for commodities Aluminum, Coal, Copper, Lamb, Lead, Nickel, Rice, Tin and Zinc); imports to developed countries are used as a proxy for exports from developing countries:

(a) US Geological Survey;

(b) Statistical Yearbook of Canada, 1899;

(c) Annuaire Statistique de la France, Vol. 19, 1899;

(d) Entwicklung und Strukturwandlungen des Englischen Außenhandels von 1700 bis zur Gegenwart, Werner Schlote, Probleme der Weltwirtschaft, Jena Fischer, 1938;

(e) Statistical Abstract for the United Kingdom in Each of the Last Fifteen Years from 1871 to 1885, HMSO, 1986.

3. 1950-2006. Sources (for all commodities):

(a) UN International Trade Statistics Yearbook, 1951-1953;

(b) UN International Trade Statistics Yearbook, 1978, Vol. 2;

(c) UNCTADstat Commodity Trade Matrix, 1995-2009. 
Table 1. Tests for a negative trend and estimated growth rates.

\begin{tabular}{|c|c|c|c|c|c|}
\hline \multicolumn{6}{|c|}{ Panel A. 1650-2010 } \\
\hline & $t_{\beta}^{R Q F}(M U)$ & Growth Rate (\%) & $90 \%$ c.i. & $95 \%$ c.i. & $99 \%$ c.i. \\
\hline CCPI & $-16.67^{* * *}$ & -0.90 & $-0.99,-0.81$ & $-1.01,-0.80$ & $-1.04,-0.76$ \\
\hline $\mathrm{CCPI}^{\prime}$ & $-17.42^{* * *}$ & -0.86 & $-0.94,-0.78$ & $-0.96,-0.77$ & $-0.99,-0.74$ \\
\hline \multicolumn{6}{|c|}{ Panel B. 1900-2008 } \\
\hline & $t_{\beta}^{R Q F}(M U)$ & Growth Rate (\%) & $90 \%$ c.i. & $95 \%$ c.i. & $99 \%$ c.i. \\
\hline CCPI & -0.25 & -0.32 & $-2.40,+1.77$ & $-2.79,+2.16$ & $-3.56,+2.93$ \\
\hline $\mathrm{CCPI}^{\prime}$ & -0.37 & -0.35 & $-1.87,+1.18$ & $-2.16,+1.47$ & $-2.73,+2.03$ \\
\hline GYCPI & $-4.08^{* * *}$ & -0.58 & $-0.81,-0.34$ & $-0.85,-0.30$ & $-0.94,-0.21$ \\
\hline
\end{tabular}

Note: ${ }^{* * *}$ denotes rejection at the $1 \%$ significance level.

Table 2. Sequential tests for multiple breaks in level/trend.

\begin{tabular}{lrcrrc}
\hline & \multicolumn{2}{c}{ CCPI } & & \multicolumn{2}{c}{ CCPI $^{\prime}$} \\
\cline { 2 - 3 } \cline { 5 - 6 } & $F_{T}(l+1 \mid l)$ & Estimated break date $(\mathrm{s})$ & & $F_{T}(l+1 \mid l)$ & Estimated break date $(\mathrm{s})$ \\
\hline$F_{T}(1 \mid 0)$ & $7.81^{* * *}$ & 1820 & & $8.99^{* * *}$ & 1881 \\
$F_{T}(2 \mid 1)$ & $8.09^{* * *}$ & 1823,1946 & & $9.11^{* * *}$ & 1823,1946 \\
$F_{T}(3 \mid 2)$ & $15.71^{* * *}$ & $1820,1872,1946$ & & $15.64^{* * *}$ & $1820,1873,1946$ \\
\hline
\end{tabular}

Note: ${ }^{* * *}$ denotes rejection at the $1 \%$ significance level.

Table 3. Tests for a negative trend in sub-sample regimes.

\begin{tabular}{llll}
\hline & & \multicolumn{1}{c}{$\mathrm{CCPI}$} & \multicolumn{1}{c}{$\mathrm{CCPI}^{\prime}$} \\
\hline $1650-1820$ & $H_{0}: \beta=0$ & $-9.78^{* * *}$ & $-13.03^{* * *}$ \\
$1821-1872 / 3$ & $H_{0}: \beta+\gamma_{1}=0$ & -0.92 & $-2.03^{* *}$ \\
$1873 / 4-1946$ & $H_{0}: \beta+\gamma_{1}+\gamma_{2}=0$ & $-4.37^{* * *}$ & $-5.59^{* * *}$ \\
$1947-2010$ & $H_{0}: \beta+\gamma_{1}+\gamma_{2}+\gamma_{3}=0$ & $-2.29^{* *}$ & $-4.10^{* * *}$ \\
\hline
\end{tabular}

Note: ${ }^{* *}$ and ${ }^{* * *}$ denote rejection at the $5 \%$ and $1 \%$ significance levels respectively. 
Table 4. Tests for a negative trend and estimated growth rates.

\begin{tabular}{llcccc}
\hline & $t_{\beta}^{R Q F}(M U)$ & Growth Rate $(\%)$ & $90 \%$ c.i. & $95 \%$ c.i. & $99 \%$ c.i. \\
\hline UK (1650-1870) & $4.65^{* * *}$ & 1.28 & $0.83,1.74$ & $0.74,1.82$ & $0.57,1.99$ \\
World (1820-2009) & $5.44^{* * *}$ & 2.23 & $1.56,2.91$ & $1.43,3.04$ & $1.18,3.29$ \\
China (1950-2009) & $9.26^{* * *}$ & 6.24 & $5.13,7.35$ & $4.92,7.56$ & $4.51,7.96$ \\
\hline
\end{tabular}

Note: *** denotes rejection at the $1 \%$ significance level.

Table 5. Sequential tests for multiple breaks in level/trend.

\begin{tabular}{llc}
\hline & \multicolumn{2}{c}{ UK (1650-1870) } \\
\cline { 2 - 3 } & $F_{T}(l+1 \mid l)$ & Estimated break date $(\mathrm{s})$ \\
\hline$F_{T}(1 \mid 0)$ & $31.04^{* * *}$ & 1790 \\
$F_{T}(2 \mid 1)$ & $69.10^{* * *}$ & 1773,1817 \\
\hline & \multicolumn{2}{c}{ World $(1820-2009)$} \\
\cline { 2 - 3 } & $F_{T}(l+1 \mid l)$ & Estimated break date $(\mathrm{s})$ \\
\hline$F_{T}(1 \mid 0)$ & $15.13^{* * *}$ & 1933 \\
$F_{T}(2 \mid 1)$ & $23.73^{* * *}$ & 1872,1955 \\
\hline & \multicolumn{2}{c}{ China $(1950-2009)$} \\
\cline { 2 - 3 } & $F_{T}(l+1 \mid l)$ & Estimated break date $(\mathrm{s})$ \\
\hline$F_{T}(1 \mid 0)$ & $12.07^{* * *}$ & 1976 \\
\hline Note: $* * *$ & denotes rejection at the $1 \%$ significance level.
\end{tabular}


Table 6. Summary measures of cyclical components.

\begin{tabular}{cccccc}
\hline \multicolumn{5}{c}{ Panel A. CCPI } \\
\hline & s.d. $\left(L C_{t}\right)$ & s.d. $\left(S C_{t}\right)$ & $\frac{s . d .\left(L C_{t}\right)}{\text { s.d. }\left(S C_{t}+L C_{t}\right)}$ & Mean periodicity $\left(L C_{t}\right)$ & Mean periodicity $\left(S C_{t}\right)$ \\
\hline $1650-2010$ & 0.147 & 0.097 & 0.832 & 27.273 & 4.140 \\
$1650-1872$ & 0.098 & 0.095 & 0.709 & 26.571 & 4.255 \\
$1873-2010$ & 0.194 & 0.099 & 0.888 & 31.500 & 4.094 \\
$1900-2010$ & 0.220 & 0.108 & 0.895 & 31.500 & 3.815 \\
\hline \multicolumn{5}{c}{} & \multicolumn{2}{c}{ Panel B. CCPI } \\
\hline $1650-2010$ & 0.135 & 0.096 & 0.813 & Mean periodicity $\left(L C_{t}\right)$ & Mean periodicity $\left(S C_{t}\right)$ \\
$1650-1873$ & 0.098 & 0.095 & 0.710 & 27.182 & 4.140 \\
$1874-2010$ & 0.168 & 0.096 & 0.865 & 26.571 & 4.231 \\
$1900-2010$ & 0.191 & 0.104 & 0.876 & 30.500 & 4.226 \\
\hline
\end{tabular}




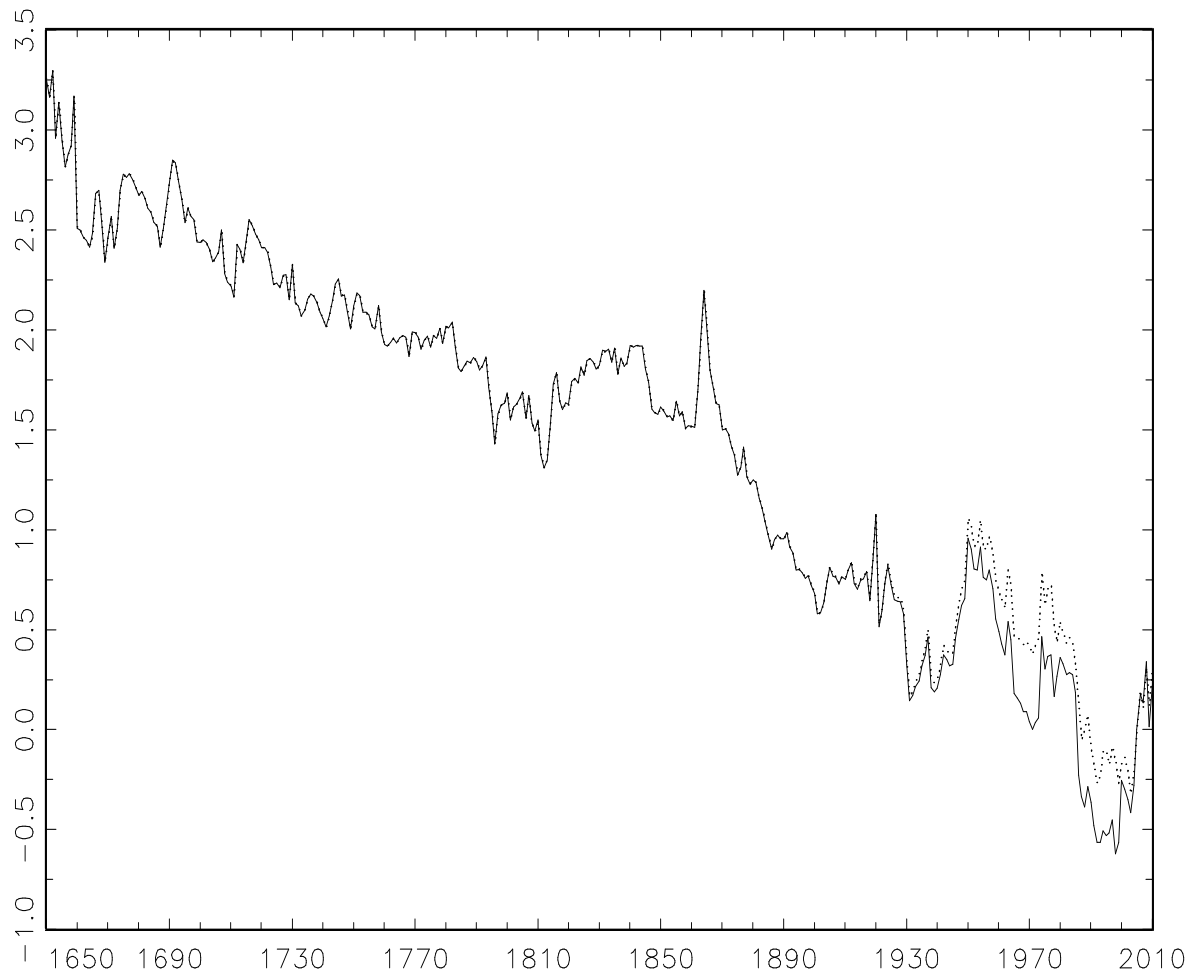

Figure 1. Logarithms of CCPI and $\mathrm{CCPI}^{\prime}, 1650-2010$ : - CCPI, $\cdots \mathrm{CCPI}^{\prime}$

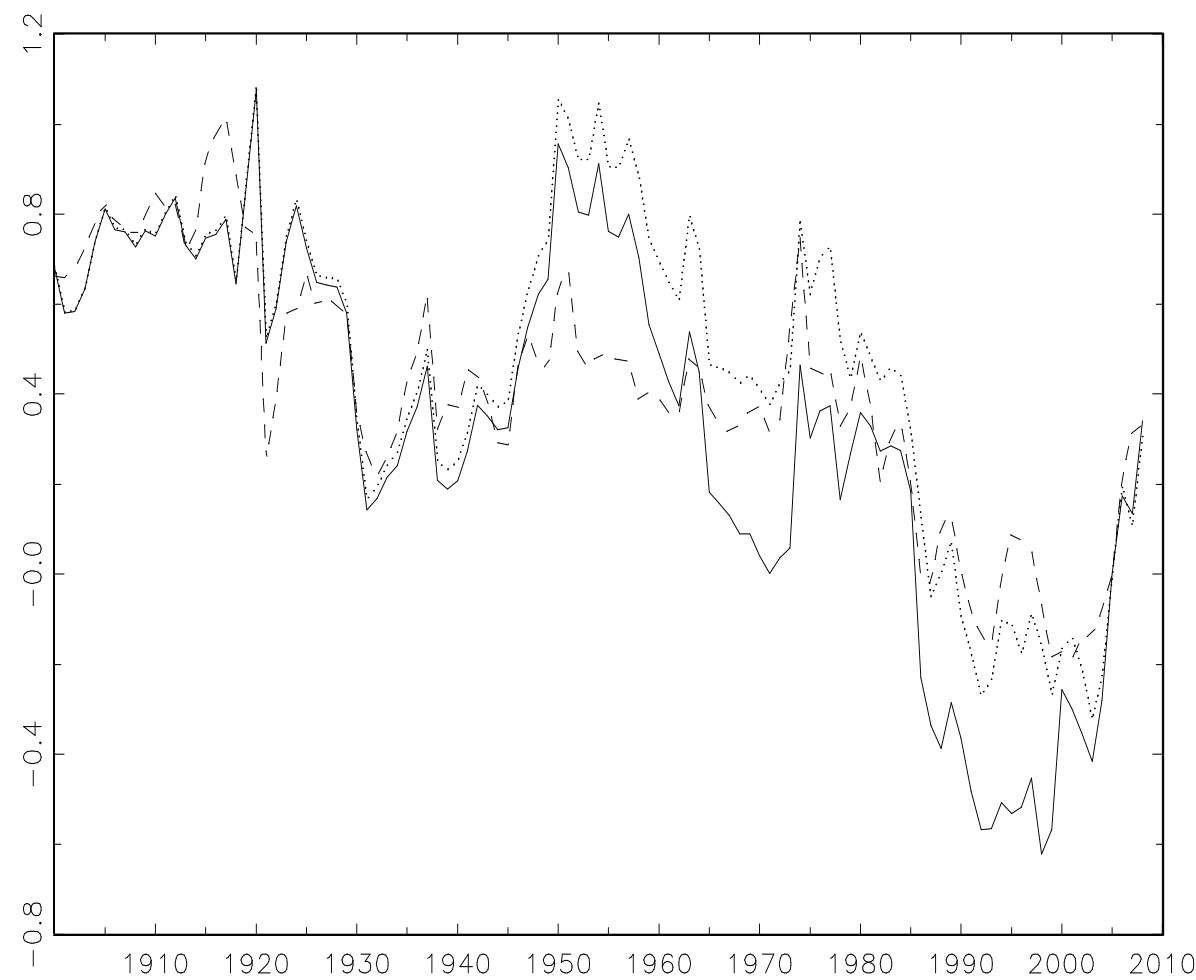

Figure 2. Logarithms of CCPI, CCPI' and GYCPI, 1900-2008: - CCPI, $\cdots$ CCPI' $^{\prime}---$ GYCPI 


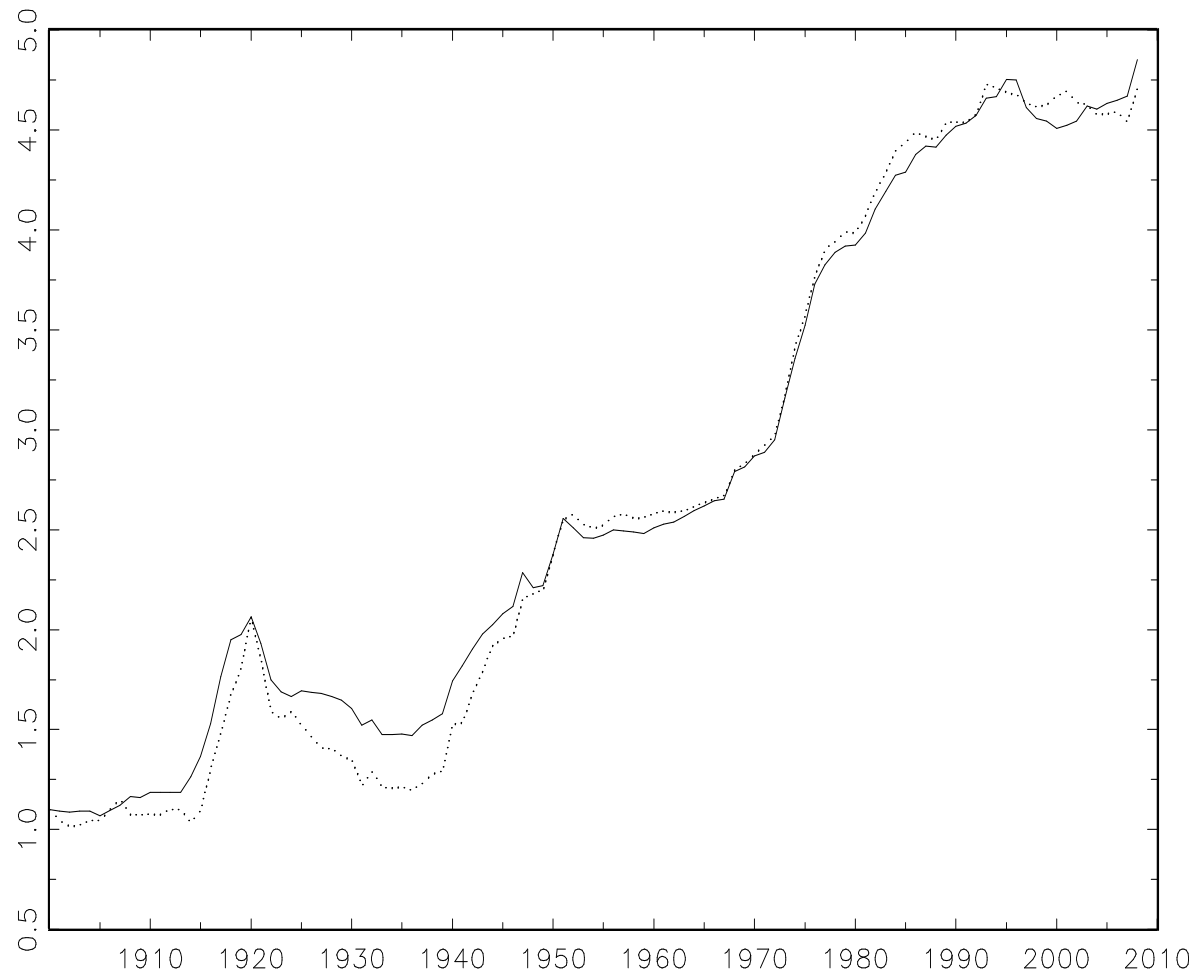

Figure 3. Logarithms of HPIM and MUV deflators, 1900-2008: — HPIM, ․ MUV 


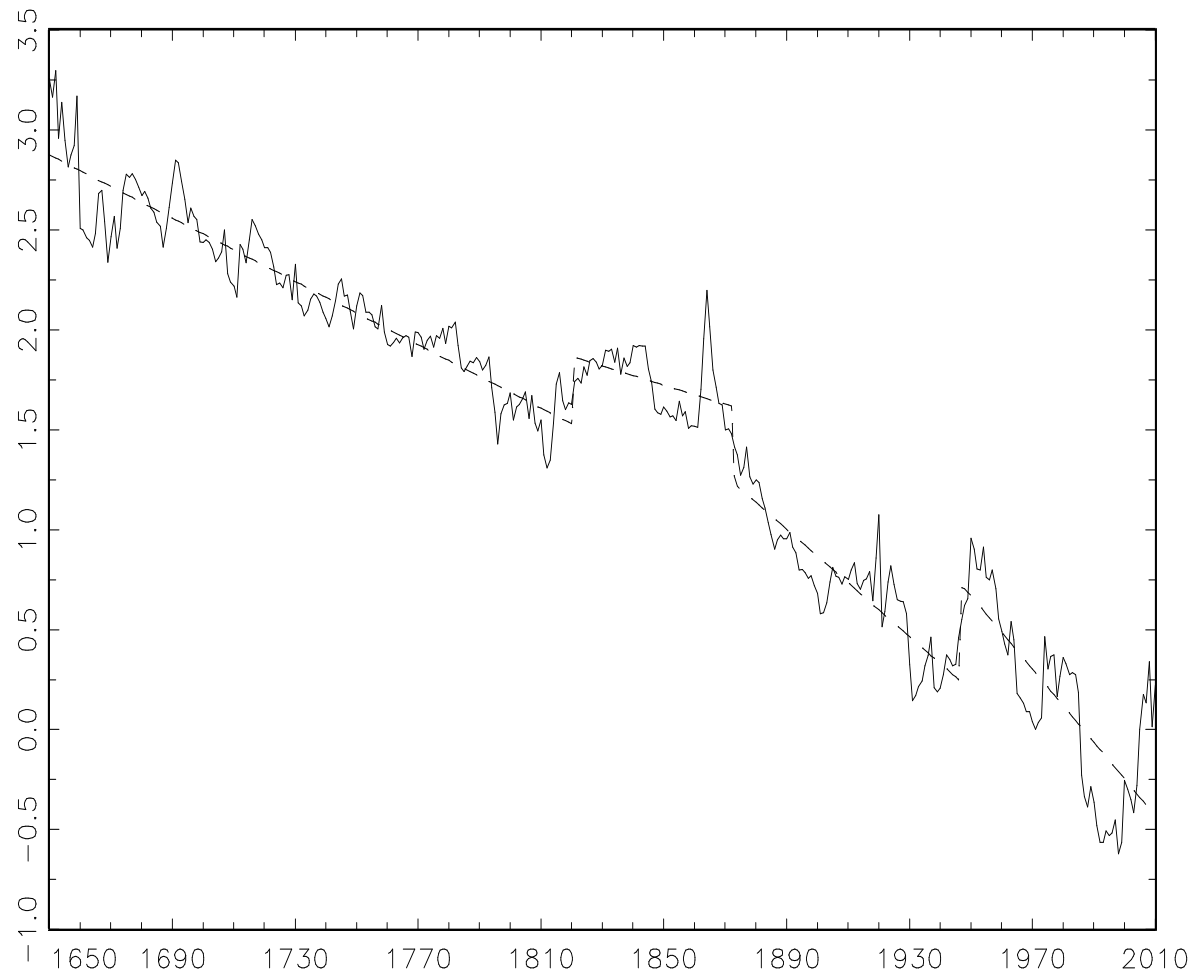

Figure 4. Logarithms of CCPI and fitted broken trend, 1650-2010: — CCPI, - - fitted values

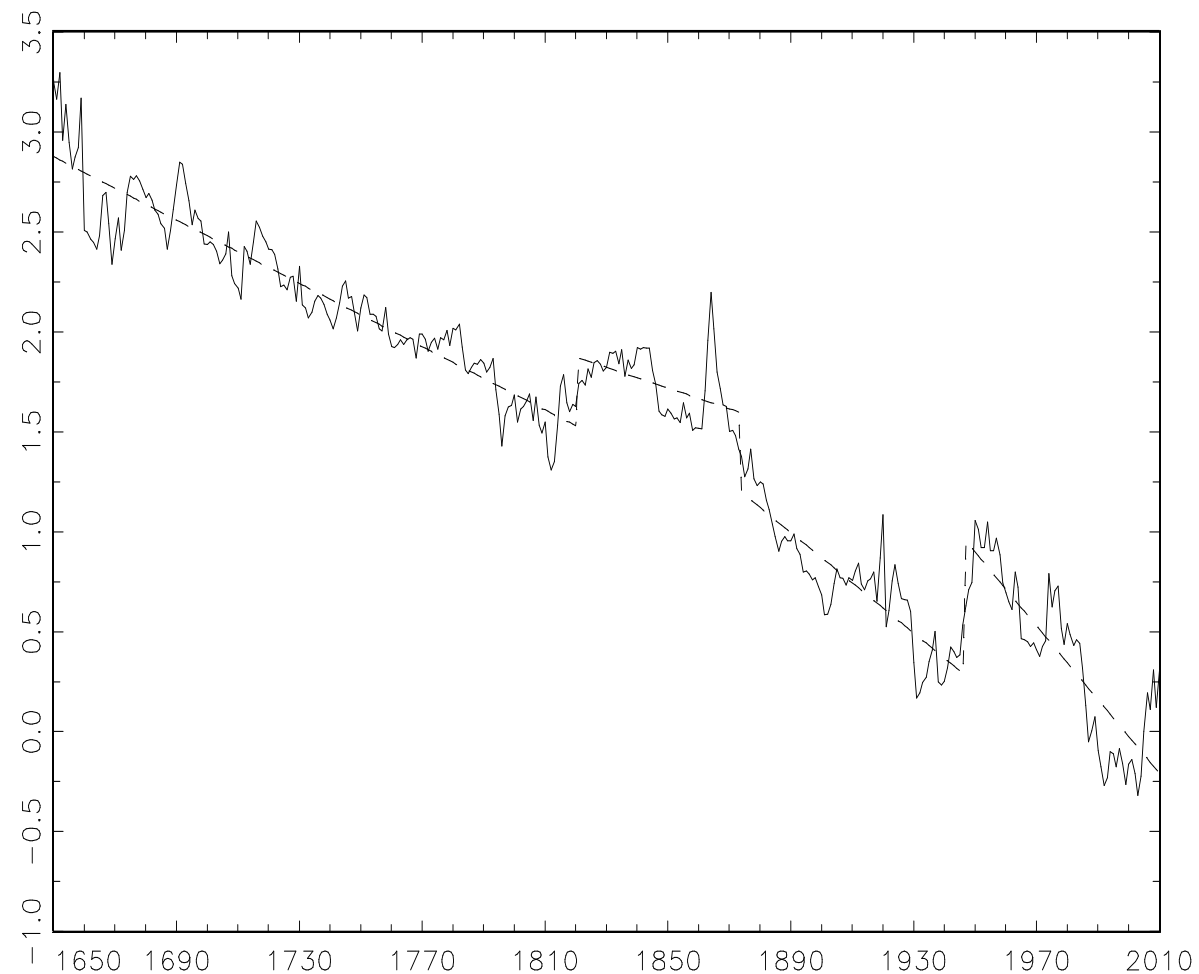

Figure 5. Logarithms of CCPI' and fitted broken trend, 1650-2010: — CCPI', - - fitted values 


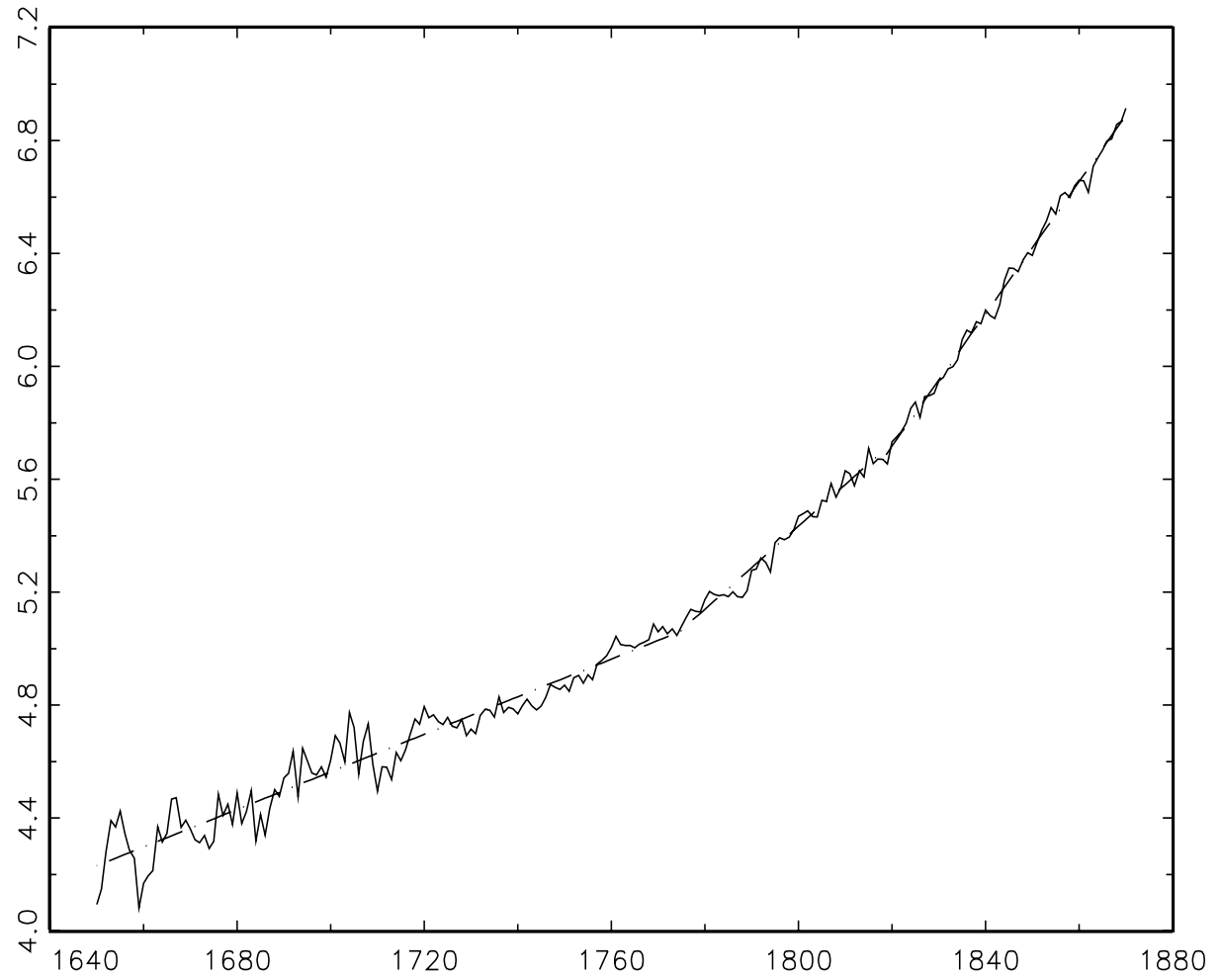

Figure 6. Logarithms of UK GDP and fitted broken trend, 1650-1870: — GDP, - - - fitted values

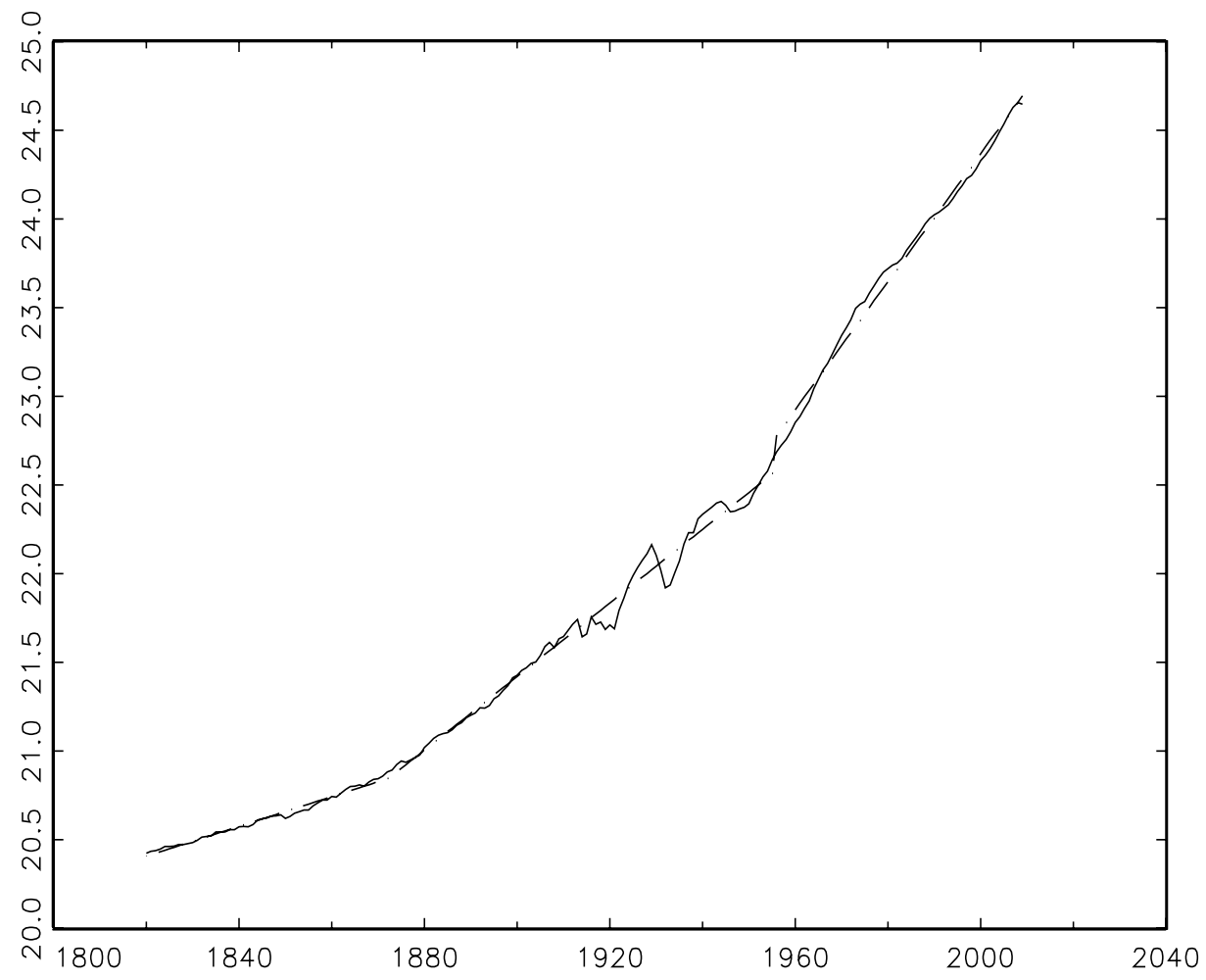

Figure 7. Logarithms of World GDP and fitted broken trend, 1820-2009: — GDP, - - - fitted values 


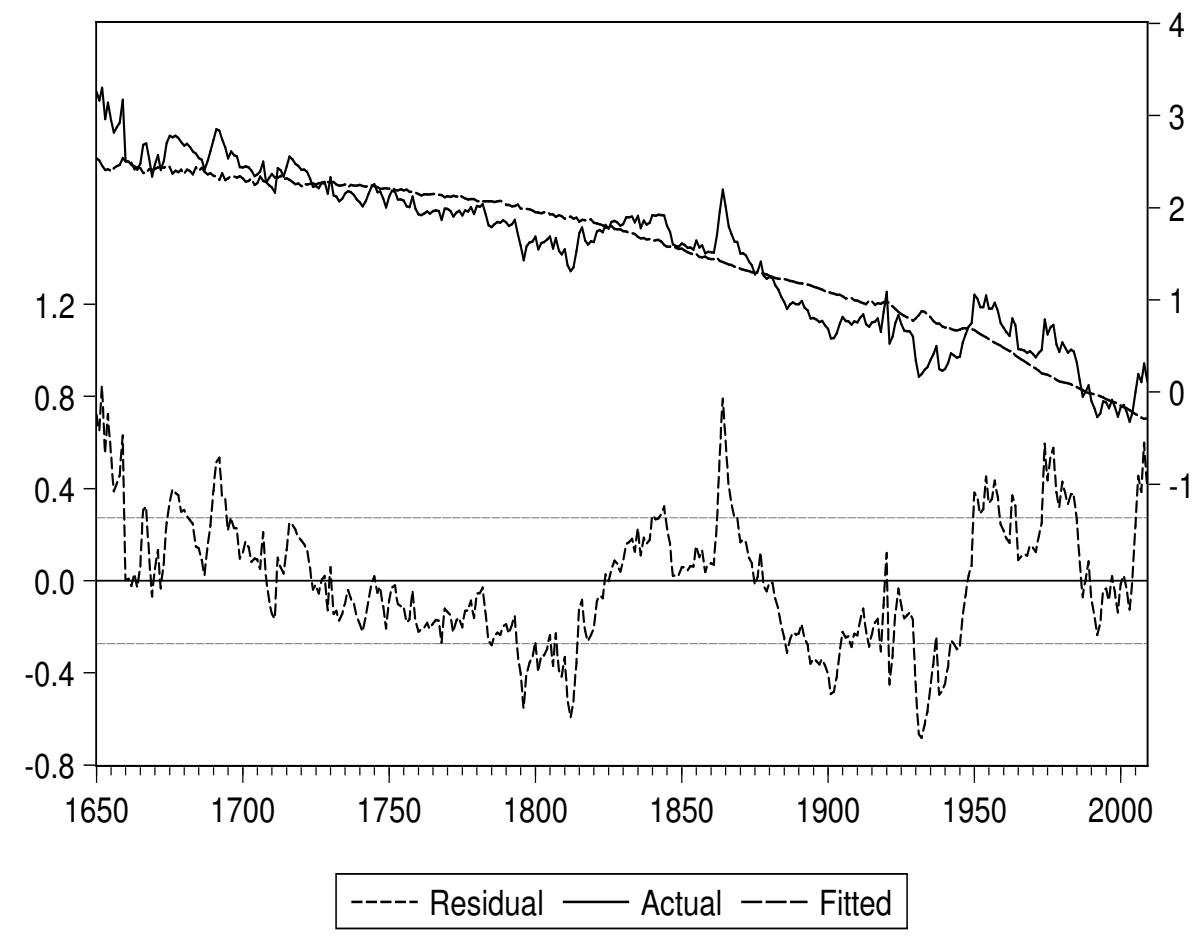

Figure 8. Logarithms of CCPI' and fitted values from 'cointegrating' regression, 1650-2009

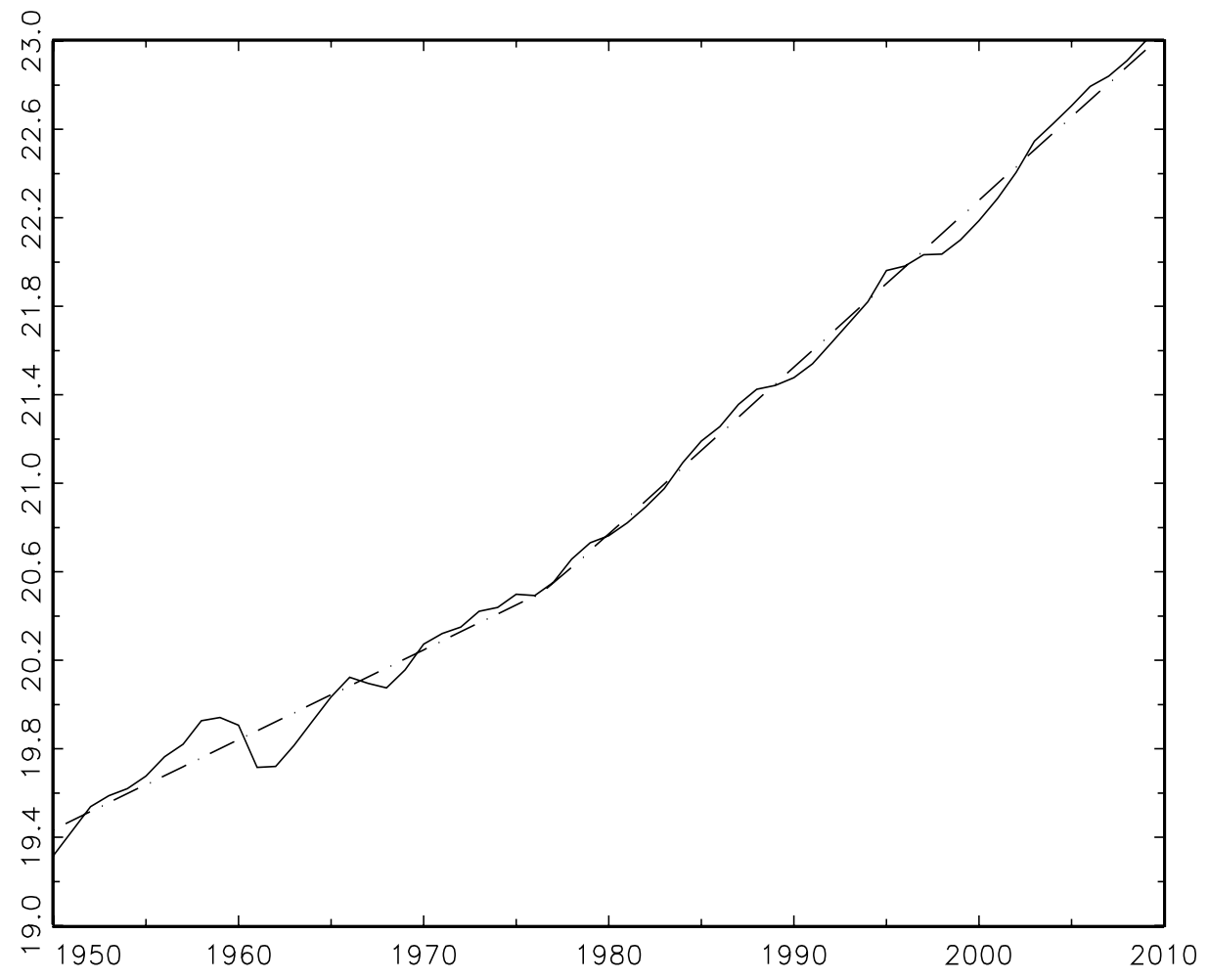

Figure 9. Logarithms of China GDP and fitted broken trend, 1950-2009: — GDP, - - - fitted values 


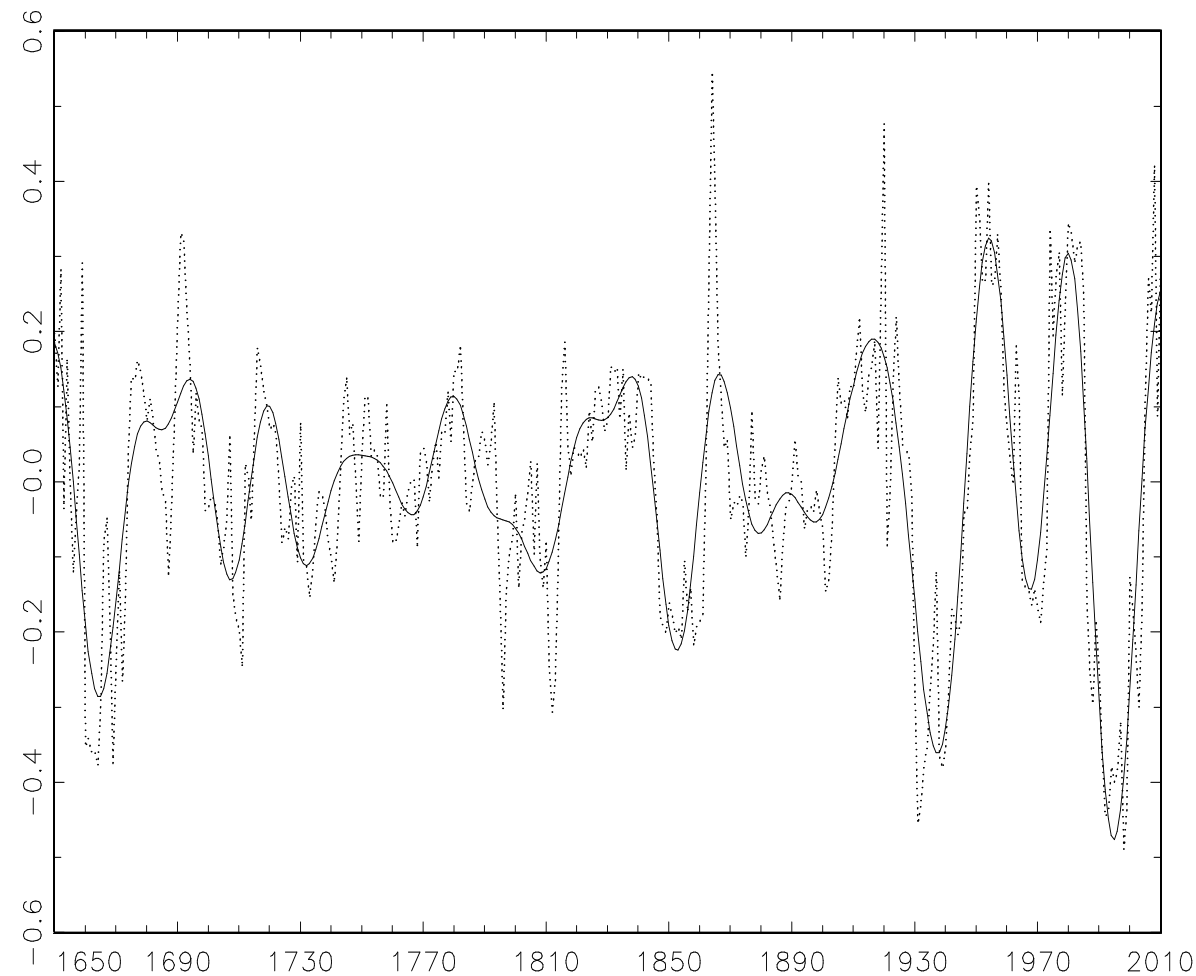

Figure 10. Cyclical components for CCPI, 1650-2010: $-L C_{t}, \cdots L C_{t}+S C_{t}$

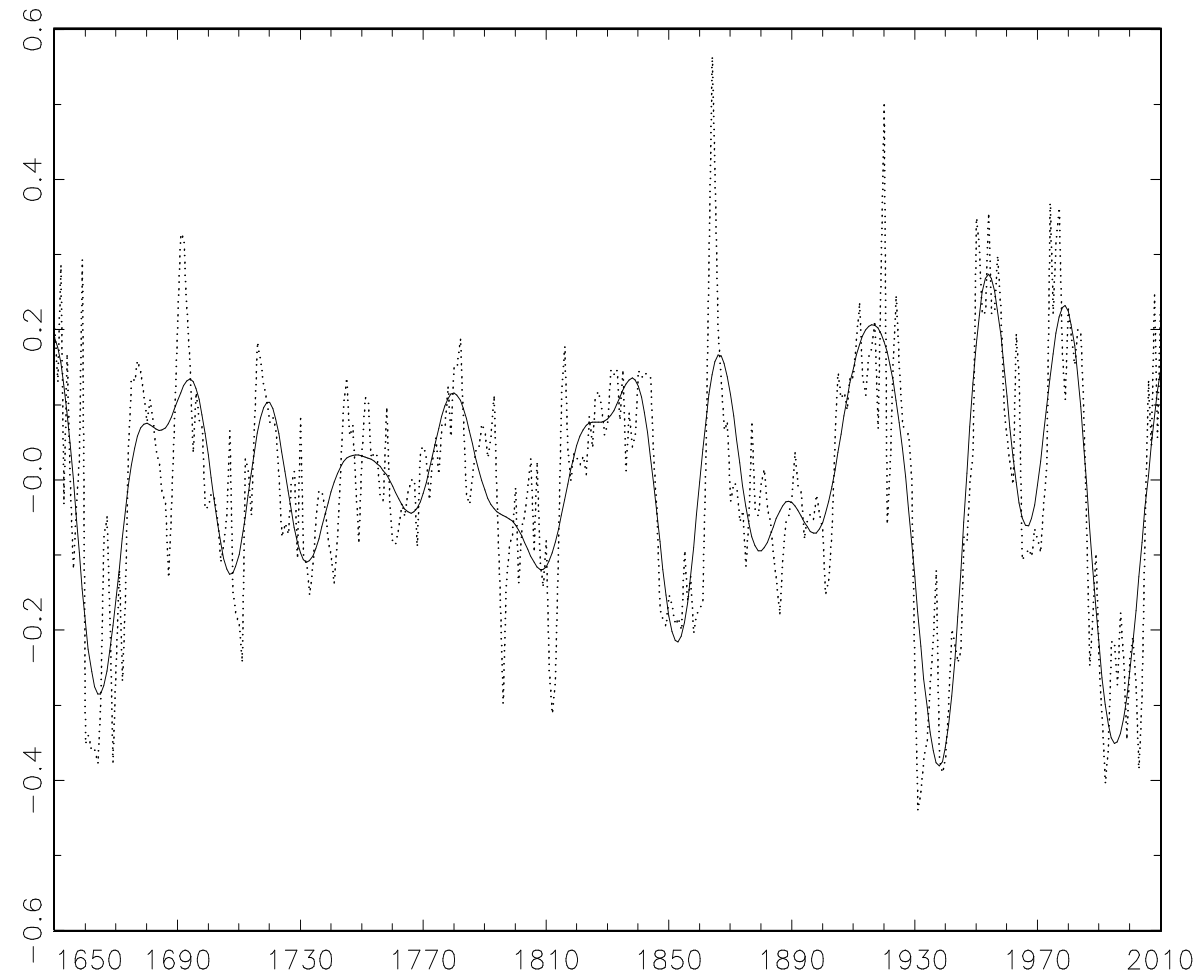

Figure 11. Cyclical components for $\mathrm{CCPI}^{\prime}, 1650-2010:-L C_{t}, \cdots L C_{t}+S C_{t}$ 